AperTO - Archivio Istituzionale Open Access dell'Università di Torino

Densification mechanisms of haplogranite glasses as a function of water content and pressure based on density and Raman data

This is a pre print version of the following article:

Original Citation:

Availability:

This version is available http://hdl.handle.net/2318/149314

since $2017-05-12 T 17: 34: 20 Z$

Published version:

DOI:10.1016/j.gca.2014.03.022

Terms of use:

Open Access

Anyone can freely access the full text of works made available as "Open Access". Works made available under a Creative Commons license can be used according to the terms and conditions of said license. Use of all other works requires consent of the right holder (author or publisher) if not exempted from copyright protection by the applicable law. 
et Cosmochimica Acta

Elsevier Editorial System(tm) for Geochimica

Manuscript Draft

Manuscript Number: W8995R3

Title: (W8995) Densification mechanisms of haplogranite glasses as a

function of water content and pressure based on density and Raman data

Article Type: Article

Corresponding Author: Dr. Paola Ardia, Ph.D.

Corresponding Author's Institution:

First Author: Paola Ardia, Ph.D.

Order of Authors: Paola Ardia, Ph.D.; A Di Muro; D Giordano; D Massare; C Sanchez-Valle; M W Schmidt

Abstract: This study investigates the effect of pressure (1 atm - 2.5 GPa) and water $(0.15,2.7,3.6$ and 5.2 wto H2O) on the network structure of alkali-rich alumino-silicate glasses synthesized at $1000{ }^{\circ} \mathrm{C}$. Density increases linearly with pressure in the water-poor composition, while in the water-rich glasses and above $1.5 \mathrm{GPa}$ densification decreases with pressure. Raman data suggest that several structural changes follow one upon another with increasing pressure and water content. The almost dry glasses undergo large modifications of the network ring structure with pressure, namely a decrease in average T-O-T angle, change in ring size statistics and possibly an increasingly homogeneous distribution of Aland Si-rich domains at high pressure. Water dissolution favors a homogenization of ring sizes at low pressures. Pressure essentially induces a decrease in the average intertetrahedral angle and, above 1.5 GPa, a possible redistribution of Al/Si-rich regions. Pressure induces an increase in $\mathrm{O}-\mathrm{H}$ bonding but decreases the $\mathrm{O}-\mathrm{H}$ bond strength. The observed structural modifications are consistent with the decreasing net effect of pressure on viscosity as temperature and water increase through variation of the activation volume of viscosity. 


\title{
Densification mechanisms of haplogranite glasses as a function of water content and pressure based on density and Raman data
}

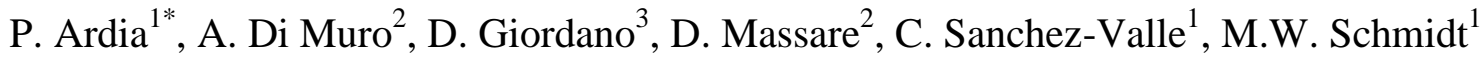

1) Department of Earth Sciences, ETH, Sonneggstrasse 5, 8092 Zurich, Switzerland

2) Laboratoire de Géologie des Systèmes Volcaniques, IPGP UMR 7154, 4 Place Jussieu, 75005 Paris, France

3) Dipartimento di Scienze della Terra, Universita' degli Studi di Torino, Via Valperga Caluso 35, 10125 Torino, Italia

*) Corresponding author, paola.ardia@gmail.com

\section{ABSTRACT}

This study investigates the effect of pressure $(1 \mathrm{~atm}-2.5 \mathrm{GPa})$ and water $(0.15,2.7,3.6$ and $5.2 \mathrm{wt} \%$ $\mathrm{H}_{2} \mathrm{O}$ ) on the network structure of alkali-rich alumino-silicate glasses synthesized at $1000{ }^{\circ} \mathrm{C}$. Density increases linearly with pressure in the water-poor composition, while in the water-rich glasses and above 1.5 GPa densification decreases with pressure. Raman data suggest that several structural changes follow one upon another with increasing pressure and water content. The almost dry glasses undergo large modifications of the network ring structure with pressure, namely a decrease in average T-O-T angle, change in ring size statistics and possibly an increasingly homogeneous distribution of Al- and Si-rich domains at high pressure. Water dissolution favors a homogenization of ring sizes at low pressures. Pressure essentially induces a decrease in the average intertetrahedral angle and, above $1.5 \mathrm{GPa}$, a possible redistribution of $\mathrm{Al} / \mathrm{Si}$-rich regions. Pressure induces an increase in $\mathrm{O}-\mathrm{H}$ bonding but decreases the $\mathrm{O}-\mathrm{H}$ bond strength. The observed structural modifications are consistent with the decreasing net effect of pressure on viscosity as temperature and water increase through variation of the activation volume of viscosity.

\section{INTRODUCTION}

The structural evolution of alkali and silica rich melts and glasses with pressure and dissolved total water contents $\left(\mathrm{H}_{2} \mathrm{O}_{\mathrm{T}}\right)$ is crucial for understanding the physical-chemical properties of silicic (rhyolitic, phonolitic or trachytic) magmas at crustal depths and, eventually, for modelling intrusive and eruptive processes. Considerable effort has been devoted to interpreting changes of bulk properties such as density and viscosity in Si-rich alumino-silicate melts in terms of short- and medium-range structural variations (Mysen et al., 1980a; Mysen and Virgo 1986; Matson et al:, 
1986; Lange and Carmichael, 1987, 1989; Okuno et al, 1996; Zotov and Keppler, 1998; Zotov, 2003; Allwardt et al., 2007). Pressure, temperature and dissolved water content play contrasting roles on liquid structural rearrangement and physico-chemical properties. Density decreases with increasing temperature and bulk water content due to thermal expansivity and to the large molar volume of "water" (sum of hydroxyl $\mathrm{OH}$ and molecular water $\mathrm{H}_{2} \mathrm{O}$; Ochs and Lange, 1999; Richet et al., 2000). In haplogranite melts, water has a major effect on melt and glass properties and its solubility is a positive function of pressure, alkali ratio $(\mathrm{Na} / \mathrm{K})$ and, subordinately, of temperature (Holtz et al., 1992; Acosta-Virgil et al., 2005; Ardia et al., 2008). Conversely, compression results in network densification and a linear increase in bulk density ( 1 atm to $2 \mathrm{GPa}$, Kushiro, 1978; 2.6 to $5.3 \mathrm{GPa}$, Suzuki et al., 2002). Similarly, the viscosity of silicic melts is drastically affected by temperature, water-content and pressure (Shaw, 1963; Hess and Dingwell, 1996; Dingwell et al., 1996, Ardia et al., 2008; Giordano et al., 2008a, del Gaudio and Behrens, 2009; Hui et al., 2009). At high temperature, both the first compression applied to haplogranite melts and the first dissolution of $\mathrm{H}_{2} \mathrm{O}$ induces a stronger decrease in viscosity than subsequent increments (Kushiro, 1978; Behrens and Schulze, 2003; Ardia et al., 2008). On the other hand, pressure increases the viscosity of hydrous rhyolites at low temperatures (Hui et al., 2009). Structural models designed to interpret the effect of pressure on the properties of alkali-bearing alumino-silicate melts must therefore explain the simultaneous linear density increase and the non-linear evolution of viscosity with increasing pressure at varying water content.

Kushiro (1978) interpreted the structural evolution of albitic and silica-rich melts with increasing pressure by analogy to the structural changes observed in crystals. In this model, a gradual change of Al-coordination from IV to VI is proposed at pressures below 1.0 GPa. Alternatively, Sharma et al. (1979) suggested that the observed decrease in melt viscosity with pressure relates to ordering or reorganization of the three-dimensional network. More specifically, Seifert et al. (1982) and Mysen et al. (1983) proposed that the decrease in average T-O-T angles with pressure determines the counterintuitive decrease in viscosity with increasing density. Hochella and Brown (1985) summarized the investigations on albitic to jadeitic compositions and only report minor changes in Raman spectra up to 4.0 GPa thus discarding the possibility that Al-coordination changes would be responsible for the observed melt densification and viscosity changes. This has been further confirmed by more recent Raman spectroscopy studies (Okuno et al., 1999; Reynard et al., 1999; Shimoda et al., 2004; Champagnon et al., 2008), which investigate the effect of pressure on waterpoor natural obsidians and dry synthetic glass analogues (silica, anorthite and albite glass compositions) between $1 \mathrm{~atm}$ and $25 \mathrm{GPa}$. Spectral analysis suggests that the densification process operates through two main mechanisms, a decrease in the intertetrahedral angles (T-O-T), and a reorganization of the connected rings forming the alumino-silicate network. 
In this study, we investigate the effect of pressure on the structure of water-poor $\left(\mathrm{H}_{2} \mathrm{O}_{\mathrm{T}}: 0.15 \mathrm{wt} \%\right)$ and water-rich $\left(\mathrm{H}_{2} \mathrm{O}_{\mathrm{T}}\right.$ : 2.7-5.2 $\left.\mathrm{wt} \%\right)$ haplogranite glasses $\left(\mathrm{Qz}_{36} \mathrm{Ab}_{37} \mathrm{Or}_{27}\right)$ combining density measurements and Raman spectroscopy on isobarically quenched glasses from $1000{ }^{\circ} \mathrm{C}$ at five different pressures $(0.5,1.0,1.5,2.0$ and $2.5 \mathrm{GPa})$. High pressure glasses are compared to a reference water-poor glass relaxed at $1 \mathrm{~atm}$. Because of similarities in composition, our vibrational data are interpreted by comparison with the extensively investigated ( $\mathrm{Na}, \mathrm{K}) \mathrm{AlO}_{2}-\mathrm{SiO}_{2}$ system (Mysen et al., 1980a; Seifert et al., 1983) with special reference to silica (Champagnon et al., 1996; Okuno et al., 1999; Champagnon et al., 2008) and albite composition glasses (Kushiro, 1978; Romano et al., 2001; Suzuki et al., 2002; Behrens and Schulze, 2003; Poe et al., 2006) whose structure and physical properties are known over a broad range of pressures and temperatures.

Quenching is presumed to freeze the densest configuration attained at high pressure and the waterspeciation $\left(\mathrm{OH} / \mathrm{H}_{2} \mathrm{O}_{\mathrm{m}}\right.$ ratio) (Hui et al., 2008) at the glass transition $\left(\mathrm{T}_{\mathrm{g}}\right)$, while the purely elastic part of the deformation is eventually released during decompression. In glasses, it has been proposed that water speciation does not depend on pressure (Richet et al., 2000). This conclusion has been recently questioned for rhyolites by Hui et al. (2008), who observed a variation of water speciation with quench pressure and employed the speciation to calculate viscosities at various pressures (Hui et al., 2009). As we will show, our data suggest that densification involves a set of mechanisms, which change with increasing pressure and water content and affect the molar volume of $\mathrm{H}_{2} \mathrm{O}$, at least at pressures above $1.5 \mathrm{GPa}$.

\section{GLASS SYNTHESIS AND QUENCH CONDITIONS}

\subsection{Synthesis}

$H G G$ haplogranite glasses $\left(\mathrm{Na}_{0.56} \mathrm{~K}_{0.38} \mathrm{Al}_{0.95} \mathrm{Si}_{5.19} \mathrm{O}_{12.2}\right)$ are silica-rich $(\mathrm{Si} /(\mathrm{Si}+\mathrm{Al})=0.85)$ and slightly peralkaline $((\mathrm{Na}+\mathrm{K}) / \mathrm{Al}=1.04 ; \mathrm{Na} / \mathrm{K}=1.5)$. The starting glasses with different water contents were synthesized in a hot isostatic press (HIP) and one of those was dehydrated using a concentric cylinder technique (Ardia et al., 2008). The resulting four compositions are from the same batches used for viscosity measurements at high pressure and temperature (Ardia et al., 2008), for elasticity measurements using Brillouin spectroscopy and for ${ }^{27} \mathrm{Al}$ NMR studies (Malfait et el., 2011, 2012). Samples HGG0, HGG3, HGG4 and HGG5 correspond to haplogranite glasses with total dissolved water contents of $0.15,2.7,3.6$ and $5.2 \mathrm{wt} \%$, respectively. Water contents of the bulk glasses were determined by Karl-Fischer titration at ETH Zurich (KFT, Behrens and Stuke, 2003). Glass homogeneity was confirmed by micro-FTIR and micro-Raman analyses in Paris (Di Muro et al., 2006a) for water content, and with electron microprobe (JEOL JXA 8200) analyses of bulk 
compositions at ETH Zurich (Ardia et al., 2008). The glass samples for spectroscopic investigation were prepared in an end-loaded piston cylinder by melting the starting glasses from a previous synthesis (Ardia et al., 2008) in Pt capsules at various pressures (0.5-2.5 GPa) and a constant

111 temperature of $1000{ }^{\circ} \mathrm{C}$. Complete homogenization and relaxation were assured by keeping the melts 112 at run condition for $12 \mathrm{~h}$ for water-rich samples (HGG 3, 4, 5) and for $2 \mathrm{~h}$ for the nearly anhydrous 113 synthesis HGG0, because the synthesis using concentric cylinder already ensures homogenization 114 (Ardia et al., 2008). Samples were isobarically quenched by manually maintaining pressure. 115 Although small pressure drops cannot be excluded, they cannot be precisely evaluated and are 116 assumed to be similar for each run. The cooling rate of the end-loaded piston cylinder is 150-200 ${ }^{\circ} \mathrm{C} / \mathrm{s}$ and is assumed to be constant for each experiment. Recovered glasses were optically examined and minor quench crystallization was identified at the rims of some water-rich glasses close to the glass-capsule interface. Thin glass chips were double side polished with parallel faces for microRaman studies. Only crystal-free glassy areas not affected by cracks or bubbles were analyzed.

\subsection{Influence of pressure on glass transition temperature}

The glass transition $\left(\mathrm{T}_{g}\right)$ is a kinetic boundary between the mechanical response to an applied stress of a liquid-like viscous and solid-like elastic material, and corresponds to the temperature of quenching of the liquid structure upon cooling (Dingwell and Webb, 1990; Gottsmann et al., 2002). The glass transition temperature is associated to specific viscosity values at fixed cooling rate, but is compositional dependent (Morizet et al., 2007; Giordano et al., 2008b). The temperature interval across the glass transition depends on composition, thermal history (cooling rate) and experimentally, upon the timescale of the investigation method (Moynihan et al., 1976; Dingwell and

131 Webb, 1990; Moynihan, 1995; Giordano et al., 2005, 2008b). The structural relaxation depends on processes affecting both the viscous and elastic components (Maxwell, 1867) and, as a consequence, its mechanical and thermodynamic properties.

134 The glass transition depends on the cooling rate $(q)$ applied to a system, and can be inferred from the apparent equilibrium temperature $\left(T_{a e}\right)$ for hydrous rhyolite melts using the relationship (Scherer, 1984; Stevenson et al., 1995; Toplis et al., 2001; Gottsmann et al., 2002; Sipp and Richet, 2002; Zhang et al., 2003):

$$
\log \eta_{T_{g}} \approx \log \eta_{T_{a e}}=11.45-\log q
$$
where $\eta$ is the viscosity in Pa.s (Hui et al., 2009). Using a quench rate of $\mathrm{q}=150 \%$ se obtain a viscosity of $10^{9.3} \mathrm{~Pa} \cdot \mathrm{s}$. This viscosity is then used to recalculate $\mathrm{T}_{\mathrm{ae}}$ applying available models for the effect of pressure on the viscosity of rhyolitic liquids (Ardia et al., 2008 and Hui et al., 2009). The model of Ardia et al. (2008) is derived from measured viscosities of $<10^{7} \mathrm{~Pa} \cdot \mathrm{s}$ for hydrous and of $<$ 
$14310^{8} \mathrm{~Pa} \cdot \mathrm{s}$ for low water content rhyolitic liquids. The model of Hui et al. (2009) applies to high 144 viscosities $\left(10^{10}-10^{12} \mathrm{~Pa} \cdot \mathrm{s}\right)$ but is not accurate at low water contents $\left(<0.80 \mathrm{wt} \% \mathrm{H}_{2} \mathrm{O}\right)$. The viscosity 145 corresponding to the glass transition of the HGG glasses $\left(10^{9.3} \mathrm{~Pa} \cdot \mathrm{s}\right)$ is intermediate between the 146 calibration ranges of both Ardia's (2008) and Hui's (2009) models. The temperature of freezing upon 147 constant cooling (quench temperature) (Table 1) calculated with the two models differ significantly 148 for high water contents. This discrepancy occurs because the Ardia et al. (2008) model predicts a 149 decrease in quenching temperature with pressure, following the trend derived from low water content 150 glasses, whereas the Hui et al. (2009) model suggests a modest increase in quench temperature with 151 pressure (Table 1). In this study, we retain the quench temperatures for the low water content glass as 152 predicted by Ardia et al. (2009) and for the high water content glasses as calculated from Hui et al. 153 (2009). For comparison, we have evaluated $T_{a e}$ for a viscosity of $\eta=10^{12} \mathrm{~Pa} \cdot \mathrm{s}$ conventionally 154 assumed as the viscosity of the glass transition for dry glasses at 1 atm (Dingwell and Webb, 1990) 155 (Table 1). In summary, $\mathrm{T}_{\mathrm{ae}}$ decreases with increasing pressure for nearly anhydrous compositions 156 (Ardia's model), whereas at increasing water contents $\mathrm{T}_{\mathrm{ae}}$ increases with pressure (Hui's model). In 157 both models, $\mathrm{T}_{\mathrm{ae}}$ decreases with water addition at a given pressure (Table 1).

\section{METHODS}

\subsection{Density measurements}

Density measurements were performed in a pyrex pycnometer by immersion of small glass chips of cylindrical shape and ca. $1 \mathrm{~mm}$ diameter in a heavy liquid (Na-polytungstate solution). This method requires a dilution of the solution with distilled water until neutral buoyancy of the immersed glass chip is attained at room temperature. Care was taken to verify that no bubbles adhere to floating glasses that could produce erroneous density measurements. The duration of the measurements (minutes to tens of minutes) was optimized to prevent the evaporation of distilled water and to attain neutral buoyancy. Density is then determined by calculating that of the diluted heavy liquid. The accuracy of this method is estimated to $\pm 0.001-0.002 \mathrm{~g} / \mathrm{cm}^{3}$ for $0.5 \mathrm{mg}$ of sample (Popel et al., 2011). Table 2 reports average errors ( $1 \sigma$ standard deviation) of all measurements.

\subsection{Raman spectroscopy}

Raman spectra of HGG glasses (average of 3 full spectra for each glass) were obtained at room conditions in confocal configuration using two micro-Raman apparatus: a LabRam HR 800 dispersive spectrometer (Jobin-Yvon ${ }^{\circledR}$ ) at LADIR laboratory (UPMC Paris VI, France) and an inVia 
Reflex dispersive spectrometer $\left(\right.$ Renishaw $\left.^{\circledR}\right)$ at Pierre-Süe laboratory (CEA, France). Non-polarized spectra of all glass samples were acquired with the Renishaw system using a diode laser $(\lambda=488.0$ $\mathrm{nm})$ as excitation source. A sub-set of non-polarized and polarized spectra was collected with the LabRam HR800 system using the $488.0 \mathrm{~nm}$ line of an argon ion laser. Both systems are equipped with a Peltier-cooled multichannel CCD detector and a microscope that allows observation of the sample, focusing of the laser beam at the surface of the sample, and collection of the Raman signal in backscattering geometry. All spectra were collected using 1800 grooves/mm grating and edge filters were used to suppress the dominant Rayleigh scattering. These conditions permitted to optimize the intensity yield and provide the spatial resolution (ca. $1 \mu \mathrm{m}$ ) necessary to minimize the influence of physical heterogeneities such as crystals, cracks, and bubbles. The LabRam setup provides a spectral resolution of $0.6 \mathrm{~cm}^{-1} /$ pixel in the $150-1400 \mathrm{~cm}^{-1}$ range due to the long focal length $(800 \mathrm{~mm})$ whereas a resolution of $1.5 \mathrm{~cm}^{-1} /$ pixel is achieved with the Renishaw spectrometer ( $250 \mathrm{~mm}$ focal). The spectral resolution slightly decreases at higher frequencies $\left(3000-3800 \mathrm{~cm}^{-1}\right)$ to 1.0 and $2.0 \mathrm{~cm}^{-}$ 1/pixel for the LabRam and Renishaw systems, respectively. With the LabRam system, acquisition times per spectrum at a power of $7.5 \mathrm{~mW}$ were $1000 \mathrm{~s}$ for the nearly anhydrous glasses and $250 \mathrm{~s}$ for the water-rich glasses to avoid damage and instability of the sample. Measurements with the Renishaw system were conducted using about $3 \mathrm{~mW}$ power at the sample surface and reduced exposure times to $30 \mathrm{~s}$ for the high frequency domain $\left(2800-4100 \mathrm{~cm}^{-1}\right)$ and to $40 \mathrm{~s}$ for the low frequency domain $\left(150-1400 \mathrm{~cm}^{-1}\right)$.

\subsubsection{Data treatment}

High resolution polarized spectra were collected to identify the main Raman features and to accurately determine band positions and widths, and the depolarization ratios $\left(\rho_{d r}=I_{V H} / I_{V V}\right)$. A polarized band is associated with a totally symmetric vibration $\left(\rho_{\mathrm{dr}}=0\right)$, while a slightly asymmetric vibration results in depolarized bands. Conversely, the analysis of non-polarized data allows assessing and correlating the general evolution of spectra with the synthesis conditions of the samples. Raw scattered intensities I $(v)\left(I_{\text {obs }}^{\text {Stokes }}\right.$ in equation 2$)$ in Raman spectra (Fig. 1a) are frequencyand temperature-dependent, with the intensities of low-frequency bands being enhanced relative to those at high-frequencies. Therefore the raw Raman intensities $I_{o b s}^{\text {Stoks }}$ were corrected to obtain the reduced spectra $I_{\text {corr }}^{\text {Stokes }}$ (Long, 1977; Brooker et al., 1988; McMillan and Wolf, 1995; Long, 2002) that provide representative intensities for all vibrational modes (Fig1b). A linear baseline (Fig. 1a) was first fitted to the high-frequency domain $\left(>1200 \mathrm{~cm}^{-1}\right)$ and subtracted from all spectra before correcting them according to the relation: 


$$
I_{\text {coor }}^{\text {Stokes }}=I_{\text {obs }}^{\text {Stokes }} \cdot v^{* 3} \cdot\left(1-e^{-\frac{h c v}{k T}}\right) \cdot \frac{v}{\left(v^{*}-v\right)^{4}}
$$

213 where $I_{o b s}^{\text {Stokes }}$ is the measured intensity, $v^{*}$ the wavenumber of the incident laser light, $v$ the measured 214 wavenumber, both in $\mathrm{cm}^{-1}, T$ temperature in $\mathrm{K}, c$ the speed of light $\left(\mathrm{ms}^{-1}\right)$ and $k\left(1.3810^{-23} \mathrm{JK}^{-1}\right)$ and $215 h\left(6.6310^{-34} \mathrm{Js}\right)$ the Boltzmann and Planck constants, respectively (Fig. 1b). In the analysis of the 216 OH-stretching domain (2900-4000 $\mathrm{cm}^{-1}$ ), a cubic baseline was subtracted (Fig. 2) (Zajacz et al., 217 2005; Behrens et al., 2006; Di Muro et al., 2006a). All spectra were normalized to the intensity of the 218 most intense observed band at ca. $490 \mathrm{~cm}^{-1}$ and smoothed using the Loess algorithm (3\%) (Figs. 1c, 219 2) before performing spectral deconvolution using the software PeakFit ${ }^{(\mathrm{R})}$. All intensities and 220 intensity changes reported in the following are normalized intensities (N.I.).

\section{RESULTS}

\subsection{Density}

Figure 3a reports the measured densities of HGG glasses (Table 2), compared with that of dry albitic glasses (Kushiro, 1978), and calculated densities of rhyolitic glasses following Withers and Behrens (1999). Densities increase linearly with quench pressure for the dry albitic and almost dry haplogranitic (HGG0) compositions, following parallel trends. The density of HGG0 is 1.4-2.5\% lower than that of dry albitic glass in the investigated pressure range. The densities of hydrous haplogranitic glasses also increase linearly with pressure up to $1.5 \mathrm{GPa}$ for HGG3 and HGG4, and to 1.0 GPa for HGG5, respectively. Above these pressures, density increase levels off.

233 Figure $3 \mathrm{~b}$ shows the evolution of glass densities as a function of water content. Density decreases linearly with increasing dissolved $\mathrm{H}_{2} \mathrm{O}$ at a given pressure, and with a rate that is similar over the whole explored pressure range. Withers and Behrens (1999) suggested that quench rate, together with water content, influence glass densities. In fact, lower densities in rhyolites are found for high quench rates $(>100 \%$ s; at $0.3 \mathrm{GPa}$ ), while slower cooling (ca. 100-150\% $/ \mathrm{min}$; at $0.5 \mathrm{GPa}$ ) results in slightly higher glass densities. Our density data on $\mathrm{HGG}$ glasses from $0.5 \mathrm{GPa}$ are very close to those of Withers and Behrens (1999) for fast quenched rhyolites from $0.3 \mathrm{GPa}$, in agreement with the finding that fast quench glasses have lower densities. The almost constant difference between our glasses quenched at various pressures and the rhyolitic glasses obtained by slow cooling (Withers and Behrens, 1999) indicates that our glasses retained the effect at high pressure upon cooling. Pressure increases the density of glasses with the exception of one hydrous glass of the HGG4 set, where the glass synthesized at $2.5 \mathrm{GPa}$ has a lower density than that at $1.5 \mathrm{GPa}$ (Fig. 3a). This 
behavior may be related to partial crystallization and cracking upon quench and therefore the spectroscopic properties of the HGG4/2.5 GPa sample will not be discussed further.

\subsection{Partial molar volumes of water}

Figure 4 and Table 3 show the calculated ambient molar volumes for HGG glasses synthesized at various pressures, together with data for a set of albitic and rhyolitic compositions (Richet et al., 2000). Molar volumes derived from high-pressure synthesis are up to $6.5 \%$ lower than those derived from low-pressure runs and are very similar for the albitic, most of the rhyolitic and HGG glasses (Table 3). Only the rhyolitic glasses of Withers and Behrens (1999) have an opposite trend that would result from the inverse relation of density as a function of synthesis pressure caused by different quench rates. The linear variation of molar volume as a function of the molar fraction of dissolved water (Fig. 4) indicates an almost constant partial molar volume of water $\left(\mathrm{V}^{*}{ }_{\mathrm{H} 2 \mathrm{O}}\right)$, within experimental uncertainty (Table 3). This is in agreement with Richet et al. (2000) who reported a constant $\mathrm{V}^{*}{ }_{\mathrm{H} 2 \mathrm{O}}$ of $12.0 \pm 0.5 \mathrm{~cm}^{3} / \mathrm{mol}$ for albitic and rhyolitic compositions. In this study, a $\mathrm{V}^{*}{ }_{\mathrm{H} 2 \mathrm{O}}$ of $12.1 \pm 1.0 \mathrm{~cm}^{3} / \mathrm{mol}$ is obtained for pressures to $1.5 \mathrm{GPa}$, in agreement with Richet et al. (2000) (Fig. 4; Table 3). However, the $\mathrm{V}^{*}{ }_{\mathrm{H} 2 \mathrm{O}}$ increases to $13.7 \pm 1.0 \mathrm{~cm}^{3} / \mathrm{mol}$ at $2.5 \mathrm{GPa}$ and is associated with a smoother increase in density at high pressure.

\subsection{Spectra analysis}

\subsubsection{Raman spectra general features and deconvolution strategy}

The unpolarized Raman raw spectra of HGG glasses display broad bands typical of amorphous materials (Fig. 5). Three main envelopes can be identified in the low- (150-650 $\mathrm{cm}^{-1}$; LF intensity envelope), intermediate- (650-850 $\mathrm{cm}^{-1}$; MF intensity envelope) and high- $\left(850-1250 \mathrm{~cm}^{-1}\right.$; HF intensity envelope) frequency ranges, respectively. In the raw spectra of water-poor HGG0 glasses, one narrow peak is observed at $490 \pm 5 \mathrm{~cm}^{-1}$ (D1) superimposed on the major broad LF envelope $\left(465 \pm 5 \mathrm{~cm}^{-1}\right)$ and an additional shoulder, which peaks at $600 \pm 5 \mathrm{~cm}^{-1}$ (D2), is observed on the high frequency part of the same envelope (Fig. 5a) (Pasquarello and Car, 1998; Ruiz et al., 2002, Thao To et al., 2008). The water region $3000-3700 \mathrm{~cm}^{-1}$ is characterized by a broad and asymmetric band in all HGG glasses that is attributed to the stretching of $\mathrm{OH}$ units with variable degrees of hydrogen bonding as will be discussed further (Behrens et al., 2006; Di Muro et al., 2006a) (Fig. 2). Collected polarized spectra were used to guide the deconvolution of the HF envelope in unpolarized spectra, in order to describe the spectral evolution with pressure and water increase. Inspection of 
shoulders occurring in both parallel (VV) and perpendicular $(\mathrm{VH})$ polarized spectra constrains the 281 adopted deconvolution strategy (Figs. 5, 6). Band positions, intensities and depolarization ratios were obtained as follows: The polarized MF and HF envelopes of water-poor and water-rich glasses quenched at low pressure were initially deconvoluted using 6 Gaussian bands, 5 bands corresponding to the HF envelope (as Seifert et al., 1982; Mysen and Frantz, 1994), in addition to a band at $800 \mathrm{~cm}^{-}$

${ }^{1}$ in the MF envelope taken as lower limit for the deconvolution. In a first step, all parameters were free and unconstrained in the fitting of the polarized spectra. We observe that the resulting frequencies of the deconvolution bands are very similar for water-poor and hydrous glasses. Therefore, the HF envelope of the unpolarized spectra was deconvoluted by maintaining deconvolution band position and width/intensity-ratio constant, only allowing for variation in the band relative intensity (Fig. 6). This strategy was chosen to minimize the error associated with deconvolution and to simplify comparison among spectra obtained at variable pressures and water contents (Fig. 6).

Deconvolution demonstrates that the main LF envelope and the D1 and D2 bands are highly polarized, whereas the band at $800 \mathrm{~cm}^{-1}$ in the MF spectral range is almost depolarized $\left(\rho_{d r}=0.30\right.$ 0.18; Table 3). The HF intensity envelope has a variable degree of polarization that evolves with frequency and water content (Table 4). In the water-poor HGG0 glass, the high wavenumber region of the HF envelope $\left(>1100 \mathrm{~cm}^{-1}\right)$ is highly polarized $\left(\rho_{d r}=0.08\right.$; Table 4$)$, whereas the low wavenumber region is only weakly polarized $\left(\rho_{d r}=0.15-0.23\right)$ (Fig. 5a; Table 4). In the low wavenumber tail of the HF envelope, the slightly polarized deconvolution band centered at about 905 $\pm 10 \mathrm{~cm}^{-1}\left(\rho_{d r}=0.15\right.$; Table 4$)$ is barely visible in the VV spectrum of water-poor glass but its intensity increases with water content (Fig. 5b). Depolarization ratios of deconvolution bands at 800 $\mathrm{cm}^{-1}$ and $905 \mathrm{~cm}^{-1}$ are similar in HGG0 and HGG3 glasses, but become 2-4 times higher for the other bands with increasing water contents. In HGG3, the high-wavenumber side becomes faintly polarized $\left(\rho_{d r}=0.20-0.17\right.$; Table 4$)$, while the low-wavenumber side is depolarized $\left(\rho_{d r}=0.55-0.20\right.$; Table 4). With increasing water contents, the peak position of the LF envelope shifts from 465 to 490 $\pm 5 \mathrm{~cm}^{-1}$ and merges with the D1 peak, while the D2 peak decreases in intensity (Fig. 5b). The observed evolution of the LF envelope could be produced by i) a decrease in D1 intensity and concomitant positive shift of the LF envelope or ii) a pronounced increase in D1 intensity with respect to the low frequency side of the main band. The LF envelope was not deconvoluted and only

\subsubsection{Raman band assignments}


314 The structure of natural and synthetic aluminosilicate glasses can be schematically described as a 315 statistical distribution of interconnected $n$-fold rings. For instance, the structures of remelted rhyolitic 316 (Zotov et al. 1992) and alkali feldspar glasses (Taylor and Brown, 1979; Seifert et al., 1981, Seifert 317 et al., 1982), whose composition is close to that of our glasses, is dominated by interconnected 6318 membered rings. The sharp D1 and D2 defect bands observed in vitreous silica have been attributed 319 to embedded populations of highly localized (i.e., non-propagating) vibrational modes of regular 320 rings with 3 and 4 members, respectively (Pasquarello and Car, 1998; Ruiz et al., 2002). Thao To et 321 al. (2008) later attributed D1 to 3- and 4-membered rings and D2 to 3-membered rings.

322 In the Raman spectra of HGG glasses, the main and broad asymmetric LF envelope $\left(150-650 \mathrm{~cm}^{-1}\right)$ is ascribed to delocalized vibrations of the aluminosilicate network that involve the displacement of bridging oxygen in intertetrahedral T-O-T linkages (McMillan et al., 1982). Specifically, the vibrations have been described either as symmetric oxygen stretching of the bent T-O-T linkages, with oxygen motion perpendicular to the T-T line, or as symmetric O-T-O angular deformation of the coupled $\mathrm{TO}_{4}$ groups (Galeener and Geissberger, 1983; Sharma et al., 1984; McMillan and Hess, 1990; Ruiz et al., 2002). Spectral composition and width of the LF envelope are thus sensitive to both the average T-O-T intertetrahedral angle and the ring distribution statistics (Ruiz et al., 2002). A decrease in the average T-O-T bond angle and a change in ring statistics both concur in shifting to higher frequency and narrowing the LF envelope. Significant increase in the proportion of 4membered rings at the expense of the largest ones is also a viable mechanism to produce the observed spectral evolution. With increasing depolymerization of the glass network, the observed LF envelope is expected to decrease in intensity relative to the HF envelope and to shift to higher frequency irrespective of the network modifying cations (Matson et al., 1983). In both synthetic and natural glasses, the $\mathrm{LF} / \mathrm{HF}$ intensity ratio exponentially decreases with increasing glass depolymerization and increases with total dissolved water content (Mysen et al., 1980b; Di Muro et al., 2006b; 2009, Mercier et al., 2009).

339 The low intensity MF envelope $\left(650-850 \mathrm{~cm}^{-1}\right)$ is attributed to the $\mathrm{Si}-\mathrm{O}$ stretching mode 340 (Kalampounias, et al., 2006) with a dominant Si motion (Matson et al., 1983), its intensity correlating 341 with silica content (Seifert et al., 1982). The main feature of the envelope at $800 \mathrm{~cm}^{-1}$ contains two 342 bands and was initially assigned to the TO-LO splitting, similarly to that observed in crystalline 343 phases and glassy $\mathrm{SiO}_{2}$ (Galeener, 1979), but later studies have challenged this interpretation 344 (Galeener and Geissberger, 1983; McMillan et al. 1994). Kalampounias et al. (2006) described the network structure of potassium tetrasilicate glass/melt as a combination of tetrahedral units arranged in open (cristobalite-like at $790 \mathrm{~cm}^{-1}$ ) and cluster (supertetrahedra at $830 \mathrm{~cm}^{-1}$ ) substructures. As this 347 feature appears insensitive to changes in pressure and water content (e.g., Fig.7), its behavior will not 348 be discussed further and we will refer to it uniquely as a feature for the sake of clarity. 
349 Conversely, the HF envelope provides information about the covalently bonded units, in Si-rich 350 glasses, in terms of $\mathrm{Q}^{n}$ species, with $n$ being the number of bridging oxygen: $\mathrm{Q}^{4}$ at $1190 \mathrm{~cm}^{-1}, \mathrm{Q}^{3}$ at $3511130 \mathrm{~cm}^{-1}$, the band at $1045 \mathrm{~cm}^{-1}$ that may reflect the amount of Bridging Oxigens in the structure 352 (BO; Mysen et al., 1980a), and $\mathrm{Q}^{2}$ at $970 \mathrm{~cm}^{-1}$. The assignment of the $900 \mathrm{~cm}^{-1}$ band is still debated 353 (see discussion). In this frequency range, there are no Raman bands attributed to the vibration of 354 network-modifying or charge-balancing cations in silica or alumino-silicate glasses. The specific 355 effect of substituting $\mathrm{Al}$ for $\mathrm{Si}$ on the HF envelope is discussed in the section 5.1. The assignment of 356 Raman bands proposed here is based on the close resemblance of HGG spectra (Figs. 1, 5, 6) with 357 those of glasses and melts along the $(\mathrm{Na}, \mathrm{K}) \mathrm{AlO}_{2}-\mathrm{SiO}_{2}$ join, especially albitic glasses and the silica358 rich glass AS50 (Seifert et al., 1982; Mysen et al., 1982; McMillan, 1984; Mysen, 1988; McMillan 359 and Wolf, 1995; Poe et al., 2001; Shimoda et al., 2004).

360 The HGG0 glass was dehydrated and relaxed at 1 atm, but residual amounts of water are still 361 observed in the high frequency domain of the Raman spectra. In this glass, a Raman band attributed 362 to $\mathrm{OH}$ units peaks at $3506 \pm 10 \mathrm{~cm}^{-1}$ and has an asymmetric negative skewed shape with a shoulder 363 at $3740 \pm 10 \mathrm{~cm}^{-1}$ (Fig. 7). Di Muro et al. (2006a) interpreted this polymodality as evidence of the 364 presence of multiple $\mathrm{OH}$ sites with variable H-bonding. According to this interpretation the main 365 shoulder is attributed to H-bonded OH units (Aines and Rossman, 1984; Mysen and Virgo, 1986), 366 while the $3740 \mathrm{~cm}^{-1}$ shoulder can be ascribed to vibrations of "free" OH units (Di Muro et al., 2006a; 367 Le Losq et al., 2013). or weakly H-bonded hydroxyl species, a feature that has been reported only in 368 glasses with very low water contents (Di Muro et al., 2006a). In the hydrous glasses, an asymmetric 369 high frequency envelope peaks at ca. $3575 \mathrm{~cm}^{-1}$ (Fig. 2). The shape and the spectral distribution of 370 this broad envelope vary with the total dissolved water content and with the composition and 371 structure of the glass (Mysen and Virgo, 1986; Di Muro et al., 2006a). The broad envelope does not 372 allow a unique frequency identification for each species. Nevertheless, it is widely recognized that 373 the lowest frequency features of the envelope $\left(3300-3550 \mathrm{~cm}^{-1}\right)$ reflects the molecular water 374 vibrations, whereas the higher frequency part $\left(>3550 \mathrm{~cm}^{-1}\right)$ is related to the hydroxyl OH vibrations 375 (Aines and Rossman, 1984; Mysen and Virgo, 1986). No tail is observed at the higher frequency side 376 corresponding to the weakly free $\mathrm{OH}$ unit observed in natural glasses with less than $1 \mathrm{wt} \%$ dissolved 377 water (Muro et al., 2006a).

\subsection{Effect of pressure on water-poor glasses (HGG0)}

381 The previous description of the spectral features of the water poor glass (HGG0) synthesized at 1 atm 382 also applies to higher pressure syntheses (Fig. 7). The LF main envelope evolves with pressure, 383 whereas changes in the MF and HF envelopes are less prominent. The LF intensity envelope 
becomes progressively narrower and peaks at higher frequencies with increasing pressure (Fig. 7;

385 Table 5). The FWHM* of the LF envelope was obtained as the width at half of the maximum height, without any specific deconvolution of the envelope (Fig. 8). The width of the LF envelope remains almost constant for the first pressure increment from 1 atm to $0.5 \mathrm{GPa}$ but decreases by about $14 \%$ between 0.5 and $2.0 \mathrm{GPa}$, levelling off in the last pressure step to $2.5 \mathrm{GPa}$ (Fig. 8). The experimental frequencies of the LF and HF envelopes (not deconvoluted) for all investigated compositions are reported as a function of pressure in Figure 9. The experimental frequency of the main envelope LF increases with pressure by $32 \pm 5 \mathrm{~cm}^{-1}$ in our pressure range ( $1 \mathrm{~atm}$ to $2.5 \mathrm{GPa}$, Fig. 9a; Table 5). The D1 defect band becomes embedded in the LF envelope at pressures higher than 2.0 GPa and then cannot be unambiguously resolved from the main feature of the LF envelope (Fig. 7). In the pressure range lower than 2.0 GPa, the frequency of the D1 defect band remains constant (Fig. 9a). In all spectra, the D2 defect band remains visible as a shoulder whose intensity (normalized to that of the LF band) decreases slightly (ca. 10\%) with pressure.

The experimental frequency of the main feature of the MF envelope remains almost constant at $800 \pm$ $10 \mathrm{~cm}^{-1}$. Its normalized intensity is constant up to $1.0 \mathrm{GPa}$ but drops by $14 \%$ and then remains constant with further pressure increase (Fig. 7). Also the experimental frequency of the main feature of the HF envelope remains mostly constant at $1132 \pm 3 \mathrm{~cm}^{-1}$ (Fig. 9d; Table 5). The only exception is for the glass synthesized at $0.5 \mathrm{GPa}$, in which the main feature of the HF envelope is located at slightly higher frequency $(+1 \%)$. The normalized intensity of this feature decreases linearly with pressure by about $15 \%$ from 1 atm to $2.5 \mathrm{GPa}$ (Fig. 9e). The spectral evolution of the HF envelope, deconvoluted as illustrated in Figure 6, shows that nearly anhydrous glasses have, within error, constant deconvoluted band areas up to $1.0 \mathrm{GPa}$ (Fig. 10a). For the same composition, higher pressures decrease the deconvoluted area of the high frequency band at $1190 \mathrm{~cm}^{-1}$ but increase that of the $970 \mathrm{~cm}^{-1}$ band (Fig. 10a).

\subsection{Effect of water at a constant pressure of $0.5 \mathrm{GPa}$}

The spectra of HGG glasses with various water contents quenched at $0.5 \mathrm{GPa}$ are compared in Fig. 11. This comparison is made initially for the low pressure range to discuss the effect of hydration separately from that of pressure. The effect of water depends on the frequency range considered. The main change in the spectra upon hydration is the appearance of a strong deconvolution band visible near $900 \mathrm{~cm}^{-1}$ (Fig. 6) that progressively increases in intensity with water content, although its experimental frequency remains constant within errors (Figs. 9c; 11). In addition, water dissolution results in a 6-12\% narrower (Fig. 8) and positively shifted (from $469 \pm 5$ to $485 \pm 5 \mathrm{~cm}^{-1}$ ) LF envelope compared to the HGG0 glass (Fig. 9a; Table 5) and in a decrease of the normalized 
intensity of the HF envelope (Fig. 9e; Table 5) whereas the MF envelope remains unaffected. In all hydrous glasses, the position of the LF envelope is positively shifted by about $20 \pm 4 \mathrm{~cm}^{-1}$ by the first water addition compared to HGG0, but then remains constant with further water addition (Fig. 9a; Table 5). The narrow defect band D1 cannot be resolved from the broad LF envelope of the waterrich glasses (Fig. 9a). The position of the HF envelope does not change significantly with increasing water content compared to the anhydrous samples (HGG0) while its normalized intensity decreases with initial addition of water, and remains almost constant at high water contents (Fig. 9e).

\subsection{Combined effect of water and pressure}

In comparison with HGG0 glasses, the spectra of hydrous glass sets (HGG3 - HGG5) display only minor changes with increasing pressure in the spectral features of the LF and MF envelopes but differences are more noticeable for the HF envelope (Fig. 12). In the HGG3 and HGG4 glass sets, increasing pressure narrows the LF envelope (see the evolution of FHMW in Fig. 8). In hydrous glasses, the weak D2 band decreases slightly (10\% or less) in intensity, showing the most pronounced decrease with the first pressure increment from 0.5 to $1.0 \mathrm{GPa}$ (Fig. 12). At 2.0 GPa, the frequency of the main feature of the LF envelope is similar in both water poor (HGG0) and waterrich glasses (Fig. 9a). The MF envelope remains at a constant position of $800 \pm 10 \mathrm{~cm}^{-1}$ in the spectra of all hydrous glass (Figs. 7, 12).

In all series of hydrous glasses, the frequency of the peak observed in the HF envelope at ca. 1130 $\mathrm{cm}^{-1}$ displays a negative frequency shift with increasing pressure to $2.5 \mathrm{GPa}$ (Fig. 12) that varies from $17 \pm 10 \mathrm{~cm}^{-1}$ for the HGG3 series to 6 and $17 \pm 10 \mathrm{~cm}^{-1}$ for the HGG4 and HGG5 glass sets, respectively (Figs. 9d, 12). In HGG3 glasses, the normalized intensity of the HF envelope decreases with increasing pressure from 1 atm to $1.5 \mathrm{GPa}$ and from 2.0 to $2.5 \mathrm{GPa}$, displaying a similar behavior as the HGG0 set (Fig. 9e). Between 1.5 and $2.0 \mathrm{GPa}$ an increase in the normalized intensities, which is directly related to the positive shift of the band, is observed. A continuous negative linear shift is observed only at P > 1.0 GPa in the HGG4 and HGG5 sets (Fig. 9e; Table 5).

Close inspection of the spectral evolution of the HF envelope prior to deconvolution reveals that the evolution of the spectra with pressure is not continuous and that distinct processes occur below and above $1.5 \mathrm{GPa}$, as already described for the water poor HGG0 set. The intensity of the slightly polarized deconvolution band near $900 \mathrm{~cm}^{-1}$ shows a positive correlation with total dissolved water content as reported by Sharma et al. (1997). In our HGG glasses the evolution of the $900 \mathrm{~cm}^{-1}$ band intensity with pressure changes at $1.5 \mathrm{GPa}$, in particular for the lower water content glasses (i.e., HGG3, Fig. 9c). At P > 1.5 GPa, a decrease in intensity with pressure is observed in the HGG3 and HGG4 sets, while HGG5 intensities remain constant. Irrespective of the pressure dependence, the 
$900 \mathrm{~cm}^{-1}$ band is always most intense in the set with the highest water content. The spectral evolution of the HF envelope, indicated by the variation of the deconvolution band at $1045 \mathrm{~cm}^{-1}$ (Fig. 10b), shows small variations with pressure only above $1.0 \mathrm{GPa}$, suggesting that structural changes related to NBO-bonding only occur above this pressure threshold. Nearly anhydrous glasses display, within error, constant deconvoluted band areas to $1.0 \mathrm{GPa}$ (Fig. 10a). Higher pressures decrease the area of the high frequency $1190 \mathrm{~cm}^{-1}$ deconvolution band but increase that of the $970 \mathrm{~cm}^{-1}$ deconvolution band (Fig. 10a). The HF envelope for the HGG3 glass displays a similar evolution with pressure, but variations are within experimental errors. The glasses with higher water contents (HGG4 and HGG5) show smaller variations with pressure that become apparent only above $1.5 \mathrm{GPa}$.

\subsection{Effect of pressure on $\mathrm{OH}$ stretching bands}

In the high-frequency range (3000-4000 $\left.\mathrm{cm}^{-1}\right)$, HGG Raman spectra show a broad and asymmetric envelope. As in spectra of both natural and synthetic glasses and melts, the intensity (relative to the low-frequency envelopes) of this band envelope correlates positively with the total dissolved water content (Di Muro et al., 2006). The bands convoluted to form this intensity envelope are assigned to $\mathrm{OH}$ stretching vibrations in molecular water $\left(\mathrm{H}_{2} \mathrm{O}_{\mathrm{m}}\right)$ and hydroxyl groups $(\mathrm{OH})$.

All investigated glass series display a shift of the envelope observed in the water stretching region towards lower frequencies with increasing pressure. This shift increases with the amount of dissolved water in the structure (Table 5, Fig. 7; 12). In the nearly anhydrous glasses, the envelope attributed to $\mathrm{OH}$ stretching exhibits two peaks, the most intense at $3506 \mathrm{~cm}^{-1}$ and a second one at $3740 \mathrm{~cm}^{-1}$. The main shoulder shifts rapidly to $3447 \pm 10 \mathrm{~cm}^{-1}$ as pressure increases from 1 atm to $0.5 \mathrm{GPa}$, then the shift rate with pressure decreases and at $2.5 \mathrm{GPa}$ this band locates at $3424 \pm 5 \mathrm{~cm}^{-1}$. The less intense shoulder shifts to $3635 \pm 10 \mathrm{~cm}^{-1}$ at $0.5 \mathrm{GPa}$ and is not further affected by the additional pressure increase. We note that the shape of the water envelope is strongly modified by further dissolution of water into the structure. In our hydrous glasses (HGG3 - HGG 5), stretching vibrations of $\mathrm{OH}$ (hydroxyl) and $\mathrm{H}_{2} \mathrm{O}_{\mathrm{m}}$ (molecular water) are represented by a single and broad asymmetrical band at ca. $3570 \mathrm{~cm}^{-1}$. In the HGG3 glass set $\left(2.7 \mathrm{wt} \% \mathrm{H}_{2} \mathrm{O}\right)$, the frequency of the "total water" $\left(\mathrm{OH}+\mathrm{H}_{2} \mathrm{O}_{\mathrm{m}}\right)$ Raman band is independent of pressure whereas in glasses with higher water contents, we observe a slightly negative shift of the band by about $10 \mathrm{~cm}^{-1}$ and $17 \mathrm{~cm}^{-1}$ for the HGG4 $\left(3.63 \mathrm{wt} \% \mathrm{H}_{2} \mathrm{O}\right)$ and HGG5 (5.24 wt $\% \mathrm{H}_{2} \mathrm{O}$ ) glass sets as pressure increases from 0.5 to $2.5 \mathrm{GPa}$ (Table 5, Fig. 12). In the water-rich glasses HGG4 and HGG5, the rate of shift with pressures increases above 1.5 GPa.

\section{DISCUSSION}




\subsection{Dry Haplogranite glass structure}

Melts and glasses along the $(\mathrm{Na}, \mathrm{K}) \mathrm{AlO}_{2}-\mathrm{SiO}_{2}$ join consist of a three-dimensional array of interconnected silica and alumina tetrahedra where alkalis fully charge-balance the $\mathrm{Al}^{3+}$ cations substituting for $\mathrm{Si}^{4+}$ in 4-fold coordination (Mysen, 1988). Although the presence of non-bridging oxygens in our HGG compositions cannot be ruled out following previous studies on highly polymerized anhydrous alkali- and alkaline-earth aluminosilicate glasses and liquids (e.g., Toplis et al., 1997; Mysen and Toplis, 2007; Neuville et al., 2008), NMR studies performed on the HGG samples show that high coordinated Al remains below detection limit (1-2\%), suggesting that NBOs are minor species on our samples (Malfait et al., 2012).

Two main groups of structural models have been proposed in the literature for $(\mathrm{Na}, \mathrm{K}) \mathrm{AlO}_{2}-\mathrm{SiO}_{2}$ glasses and are summarized here:

501 Type 1 models ("two-unit models"): the Raman spectrum of $\mathrm{SiO}_{2}$ glass displays two depolarized 502 bands at $1060 \mathrm{~cm}^{-1}$ (band A) and $1190 \mathrm{~cm}^{-1}$ (band B) that have been attributed to the stretch of Si-O 503 bonds in two units with different intertetrahedral angles in the three-dimensional network (Mysen et 504 al., 1980a; Seifert et al., 1982). In this model, band $A$ is associated with the small-angle unit and band $505 B$ with the large-angle unit. Following Mysen et al. (1980a), the $A$ and $B$ depolarized bands are retained in the spectra of $(\mathrm{Na}, \mathrm{K}) \mathrm{AlO}_{2}-\mathrm{SiO}_{2}$ glasses and their position shifts toward lower frequencies with increasing temperature and $\mathrm{Al} /(\mathrm{Al}+\mathrm{Si})$ ratio due to the elongation and weakening of $\mathrm{T}-\mathrm{O}$ bonds upon substitution of $\mathrm{Si}$ by $\mathrm{Al}$. The $A$ and $B$ bands correspond to vibrations of two distinct threedimensional units with the $B$ band being associated to the unit with higher $\mathrm{Al} /(\mathrm{Al}+\mathrm{Si})$ ratio whose intensity is predicted to increase with pressure. Mysen et al. (1982) further extended this model by defining four deconvolution bands in the HF intensity envelope of glasses along the $\mathrm{NaAlO}_{2}-\mathrm{SiO}_{2}$, $\mathrm{CaAl}_{2} \mathrm{O}_{4}-\mathrm{SiO}_{2}$, and $\mathrm{MgAl}_{2} \mathrm{O}_{4}-\mathrm{SiO}_{2}$ joins. These four bands are centered at $1009 \mathrm{~cm}^{-1}, 1066 \mathrm{~cm}^{-1}$, $1127 \mathrm{~cm}^{-1}$ and $1190 \mathrm{~cm}^{-1}$, respectively, in the spectrum of AS50 glass (Mysen et al., 1982; Seifert et al., 1982) similar in composition to HGG0. In situ studies along the $\mathrm{NaAlSiO}_{2}-\mathrm{SiO}_{2}$ join $(\mathrm{Neuville}$ and Mysen, 1996) have shown that the 1190/1127 intensity ratio increases with temperature but decreases with pressure (Mysen et al., 1983). The $1190 \mathrm{~cm}^{-1}$ band should correspond to "expanded" Al-Si rings ("unit I") with large inter-tetrahedral angle, while the $1127 \mathrm{~cm}^{-1}$ band is interpreted as the vibration of "dense" Al-Si rings ("unit II") with small inter-tetrahedral angle. Several observations indicate that this model cannot be fully applied to our haplogranite glasses: For instance, the 1190 and $1127 \mathrm{~cm}^{-1}$ bands are polarized in the almost dry HGG0 glasses but only moderately polarized in our hydrous glasses (Fig. 5; Tab. 4). The $1190 \mathrm{~cm}^{-1}$ band intensity decreases with pressure as predicted by the above model. Nevertheless, this decrease occurs only above a 
threshold pressure of 0.5-1.0 GPa. Most important, a linear increase of the $1127 \mathrm{~cm}^{-1}$ band intensity with pressure is not observed for deconvoluted spectra, except perhaps in the HGG3 set (Fig. 10). Type 2 models ("one-unit models"): In Al-bearing fully polymerized glasses, variably polarized deconvolution bands in the HF envelope are attributed to vibrations in rings (i.e. 6-membered rings in albite glass) whose frequency decrease with increasing $\mathrm{Al} /(\mathrm{Al}+\mathrm{Si})$ ratio (McMillan et al., 1982; Sharma et al., 1997). In HGG, the polarization of the bands at $1190 \mathrm{~cm}^{-1}$ and $1140 \mathrm{~cm}^{-1}$ indicate that they correspond to symmetric stretching vibrations of $\mathrm{Q}^{4}(\mathrm{Si})$ and $\mathrm{Q}^{4}(1 \mathrm{Al})$ units, respectively $\left(\mathrm{Q}^{\mathrm{n}}\right.$ : $\mathrm{TO}_{4}$ units with $\mathrm{T}=\mathrm{Al}, \mathrm{Si} ; n$ : number of bridging oxygens; the number in parenthesis indicates the number of oxygens Si tetrahedra share with Al tetrahedra). The depolarized nature of the bands at $1045 \mathrm{~cm}^{-1}$ and $970 \mathrm{~cm}^{-1}$ (Fig. 5; Table 4) indicates that they originate from anti-symmetric stretching vibrations of $\mathrm{Q}^{4}(2 \mathrm{Al})$ and $\mathrm{Q}^{4}(0 \mathrm{Al})=\mathrm{Q}^{4}(\mathrm{Si})$ units, respectively (McMillan et al., 1992; Neuville and Mysen, 1996; Mysen, 1999). Furthermore, stretching vibrations of $\mathrm{Q}^{n}$ species result in strongly polarized bands at $950\left(\mathrm{Q}^{2}\right.$ units) and $1100 \mathrm{~cm}^{-1}\left(\mathrm{Q}^{3}\right.$ units) (McMillan et al., 1992; Mysen and Frantz, 1993). The band at $1045 \mathrm{~cm}^{-1}$ has also been correlated with increasing amounts of NBO (McMillan and Wolf, 1995) and considered a doublet of $\mathrm{Q}^{2}$ (Mysen, 1988; Malfait et al., 2008). These three highly polarized bands are not observed in the HGG glasses, suggesting that alkalis already fully balance the 4-fold coordinated $\mathrm{Al}$ and that increasing amounts of dissolved $\mathrm{H}$ do not create additional NBOs (Fig. 10). Hence, on the basis of the high frequency bands measured in HGG glasses, model 2 is retained for the interpretation of the HGG glass structures presented below.

\subsection{Evolution of haplogranite glass structure with pressure}

On the basis of the above structural model, the spectroscopic observations and density data of the HGG glasses are interpreted in terms of 1) ring statistics (the relative proportions of inter-connected $n$-membered $\mathrm{Al}-\mathrm{Si}$ rings) and average T-O-T intertetrahedral angle of each ring population, 2) $\mathrm{Al} / \mathrm{Si}$ ratios in different units and 3 ) water speciation and hydrogen-bond strength.

\subsubsection{Ring statistics and ring sizes}

Upon compression, the T-O-T angle decreases and hence could lead to a modification of the ring statistics (Ruiz et al., 2002). Moreover, pressure can affect the intertetrahedral T-O-T angle by modifying the $\mathrm{Al} / \mathrm{Si}$ ratio of a given ring population. These effects are not easily discriminated by 
Raman spectroscopy. However, an evolution of ring statistics with increasing pressure and water content is suggested by the topological evolution of the LF envelope, as detailed below.

557 In the water-poor HGG0 glasses, increasing pressure progressively decreases the intensity of the D2 shoulder. This spectral evolution likely reflects a relative decrease in abundance of the smallest (3membered) rings (Pasquarello and Car, 1998; Ruiz et al., 2002, Thao To et al., 2008). As previously stated, the observed frequency increase in the peak of the LF envelope may result either from i) a positive shift of its low frequency $\left(465 \mathrm{~cm}^{-1}\right)$ side, associated or not with a decrease in D1 intensity, or ii) from a decrease in intensity of the $450 \mathrm{~cm}^{-1}$ region and a significant and concomitant increase in the intensity of the D1 band. The D1 feature correlates with the presence of both 3- and 4membered rings (Thao To et al., 2008). The decrease in the proportion of 3-membered rings, as suggested by the evolution of the D2 band, should correlate with a decrease in D1 intensity, unless a significant proportion of 4-membered rings is created at the expense of larger rings $(n>4)$.

The Raman data do not allow clarifying whether the change in the proportion of small ring populations is preceded by deformation of their internal angles. The almost constant frequencies of both D1 and D2 bands observed in our water-poor glasses suggest an absence of deformation upon pressurization to $2.5 \mathrm{GPa}$ (Figs. 7, 9a). Average internal angles of $\sim 136^{\circ}$ and $128^{\circ}$ for the small rings were calculated from our data considering the position of the LF envelope following the model of Ruiz et al. (2002). The negligible pressure-induced shift of the D1 (up to $2.0 \mathrm{GPa}$ ) and D2 bands (up to $2.5 \mathrm{GPa}$ ) contrasts with the average shift of $5.2 \mathrm{~cm}^{-1} / \mathrm{GPa}$ and $1.5 \mathrm{~cm}^{-1} / \mathrm{GPa}$ reported for these bands in the in situ high pressure Raman study of $\mathrm{SiO}_{2}$ glasses by Champagnon et al. (2008). Possibly, the progressive overlap of the D1 band and a positive shift of the $465 \mathrm{~cm}^{-1}$ band with pressure masks the expected positive shift of the D1 band in our HGG spectra. This observation may lend support to the hypothesis that the $465 \mathrm{~cm}^{-1}$ band moves to higher frequency with pressure. Alternatively, the constant frequency may arise either from i) the very low compressibility of the smaller rings, ii) from Al-Si substitution in 3- and 4-membered rings counterbalancing the net pressure effect or iii) from a partial relaxation of the internal angle of small 3-4 membered rings upon glass decompression during quench. Available data do not permit to discriminate between these processes, even if we suspect that the poor compressibility of the small rings may play a dominant role. A possible partial relaxation upon decompression should produce a broadening of the LF envelope as significant changes in $\mathrm{Al}$ coordination with increasing pressure have been ruled out by NMR analysis of the same samples (Malfait et al., 2012).

In the water-poor HGG0 glasses, the peak of the LF envelope shifts with pressure from 461 to 490 $\mathrm{cm}^{-1}$ (Figs. 7, 9a), i.e. $13 \pm 3 \mathrm{~cm}^{-1} / \mathrm{GPa}$. This rate of shift is actually in good agreement with the 10.4 $\pm 0.8 \mathrm{~cm}^{-1} / \mathrm{GPa}$ reported by Champagnon et al. (2008) for silica. We propose that this frequency change records both the narrowing of the average T-O-T angle and a re-distribution of ring 
populations, because of the decrease in relative proportion of the smallest rings $(n=3)$. Both

591 processes concur with the linear increase of density with pressure (Lipinska-Kalita et al., 2005).

592 In hydrous glasses, a slight negative shift of the LF envelope would be expected when the proportion 593 of small-sized rings decreases with pressure $(n=3,4)$. This shift cannot be resolved in our dataset. 594 Alternatively, both the populations of very large rings $(n>6)$ and small rings $(n=3,4)$ are affected 595 resulting in the almost constant position of the peak of the LF envelope of the hydrous glasses. The 596 latter would be supported by the shrinkage of the main LF envelope with pressure in all glass sets, 597 suggesting that the width of the T-O-T angle distribution becomes narrower (Fig. 8). We propose that 598 the disappearance of the large values in the angle distribution indicates a decrease in relative 599 abundance of the largest rings ( $\mathrm{n}>4)$ and is an important process of glass densification, independently 600 of water content. In fact, the shrinkage of the LF envelope parallels the evolution of the bulk glass 601 density with pressure. The specific evolution of 4-membered rings (increase at the expense of large 602 rings or decrease, like the 3-membered rings) cannot be definitively resolved with the available data 603 and requires further investigation.

\subsubsection{Units with variable Al/Si ratio}

In the water-poor HGG0 glasses, the HF envelope exhibits only minor changes with increasing pressure (Fig.7) while larger spectral changes and significant negative shifts occur in the hydrous glass sets (Figs.11, 12). These correspond to a relative decrease in intensity of the $\sim 1190 \mathrm{~cm}^{-1}$ deconvolution band and a concomitant increase in the relative intensity of the $970 \mathrm{~cm}^{-1}$ 611 deconvolution band for the intermediate water contents (e.g. HGG3, HGG4; Figs. 7, 10a, 13) at 0.5 $612 \mathrm{GPa}$. As argued above, it can be excluded that these changes correspond to a decrease in the 613 abundance of polymerized $\mathrm{Q}^{4}$ units and a concomitant increase in depolymerized $\mathrm{Q}^{2}$ units. Water addition may cause disorganization in the $\mathrm{Si}-\mathrm{Al}$ rich domains without necessarily decreasing the degree of polymerization (Zotov et al., 1992). The variations observed in our hydrous glasses upon pressure increase could be interpreted as a reorganization or increase in order of the $\mathrm{Si}-\mathrm{Al}$ domains in a given unit (Kohn et al., 1992). Accordingly, the observed small negative shift of the HF envelope 618 (Fig. 9d) should mostly relate to an intensity decrease of its high frequency $\left(1190 \mathrm{~cm}^{-1}\right)$ and an 619 intensity increase of its low frequency component $\left(970 \mathrm{~cm}^{-1}\right)$. The negative shift could also stem 620 from a decrease of the average T-O-T angle and a consequent elongation and weakening of the T-O 621 bonds (Lee et al., 2006) but none of this was observed in the LF envelope. 
625 Different mechanisms have been proposed for the incorporation of water in the silicate network. In depolymerized systems, water disrupts the T-O-T bonds and forms T-OH bonds (Xue and Kanzaki, 2008; Malfait et al. 2009). In polymerized systems, water dissolution mechanisms could occur via 1) rupture of the T-O-T bonds followed by the formation of $\mathrm{Si}-\mathrm{OH}$ and minor Al-OH units, leading to a bulk network depolymerization (Xue and Kanzaki, 2008; Malfait et al. 2009); 2) bridging to alkalis and formation of $\mathrm{M}-\mathrm{OH}$ bonding with $\mathrm{M}=\mathrm{Na}, \mathrm{K}, \mathrm{Ca}$ or $\mathrm{Mg}$ (Kohn et al., 1989; 1992; Xue and Kanzaki, 2008); or 3) by formation of $\mathrm{H}_{3} \mathrm{O}^{+}$that distorts the structure of the silicate (Sharma et al., 1996; 1997). In the water-rich HGG glasses, the D1 band cannot be resolved and the D2 band is much less intense with respect to the water-poor HGG0 glasses (Fig. 7). This observation may suggest that water dissolution destabilizes the small-sized rings $(\mathrm{n}=3)$. In all hydrous glasses, the LF feature envelope is located at higher but constant frequency $\left(480 \mathrm{~cm}^{-1}\right.$, Fig.9a) with respect to the almost dry HGG0 glasses at $1 \mathrm{~atm}-0.5 \mathrm{GPa}\left(460-470 \mathrm{~cm}^{-1}\right)$. This suggests a smaller average T-O-T angle in hydrous glasses that correlates with the smaller $d \rho / d P$ at $\mathrm{P}>1.5 \mathrm{GPa}$ compared to their nearly anhydrous counterpart (Fig. 3a). Water dissolution clearly affects the distribution of T-O-T angles. We propose that both compression of internal angles and the modification of ring statistics concur in the frequency increase of the LF envelope. If our interpretation is correct, water dissolution has a similar role as pressure increase by favoring the decrease in the population of very large (higher than 6-membered) and very small (3-membered) ring types.

\subsubsection{Hydrogen bonding strength}

Spectroscopic data summarized above (Type 2 model) do not show conclusive evidence for an increase in the proportion of NBOs in highly polymerized systems such as HGG haplogranites upon water dissolution, as the addition of alkalis does (Kohn et al., 1989; Zotov et al., 1992). This interpretation is consistent with the absence of a positive shift of the LF envelope in our hydrous glasses (to be expected for the addition of alkalis as shown by Di Muro et al. (2006a)), and with the absence of an increase in the intensity of deconvolution bands that could be related to $\mathrm{Q}^{3}$ units in the HF envelope with increasing water contents.

In our model proposed for the HGG glasses, water dissolves as i) molecular water, ii) alkali-OH complexes and iii) "bridging" $\mathrm{OH}$ groups, i.e., protons attached to a bridging oxygen in T-O-T linkages. These observations do not rule out possible T-OH linkages as proposed by Malfait (2009). Moreover, it has been shown that water, as well as excess alkalis $\left(\mathrm{Na}_{2} \mathrm{O}\right)$ lead to an increase in the Poisson's ratio of haplogranite glasses, hence suggesting a decrease in the degree of polymerization (Malfait and Sanchez-Valle, 2013). Further spectroscopic analyses are required to better understand 
the mechanisms of water incorporation in haplogranite glasses. Kohn et al. (1992) suggest that the 660 non-linear dependence of viscosity on water content may be explained by assuming that bridging 661 hydroxyl groups have a larger effect on viscosity than molecular water. In Fig. 12, a decrease of the asymmetry with water addition is observed at constant pressure. This reflects a possible decrease of the $\mathrm{OH} / \mathrm{H}_{2} \mathrm{O}_{\mathrm{m}}$ ratio with increasing total dissolved $\mathrm{H}_{2} \mathrm{O}$ in agreement with previous studies (Dixon et al., 1995; Zhang et al., 2003). Thus, the decrease in the $\mathrm{OH} / \mathrm{H}_{2} \mathrm{O}_{\mathrm{m}}$ ratio with increasing bulk water content (Stolper, 1982) is expected to reduce the effect of water on bulk viscosity. Our data suggest that initial water dissolution operates on specific sites, and is efficient in decreasing the population of both the very small and very large rings, probably due to the formation of water-rich domains as reported by Zotov et al. (1992).

In the following discussion, we assume that even if the evolution of water speciation with pressure may not be fully quenched, the main modifications on the network are still retained upon quench (Table 4). The strength of the O-H linkage depends on the short-range environment around the $\mathrm{OH}^{-}$ species and may evolve during melt/glass densification. This interpretation is based on the observation of the parallel evolution of the intensity of the Raman envelopes at $900 \mathrm{~cm}^{-1}$ and 3600 $\mathrm{cm}^{-1}$ with pressure.

The structural origin of the $900 \mathrm{~cm}^{-1}$ Raman band in hydrous glasses is still debated. In aluminosilicate glasses, a highly polarized band at this frequency has been attributed to vibration of $\mathrm{T}^{-} \mathrm{O}^{-}$ bonds in $\mathrm{Q}^{2}$ species (Mysen and Virgo, 1986). However, our depolarized Raman data exclude this interpretation for the HGG glasses as its intensity decreases or is not affected with increasing pressure (Fig. 9c). On the other hand, Sharma et al. (1996; 1997) ascribed this band to a vibration of the silicate framework associated to an anti-symmetric mode of a T-O-T group. Recent NMR investigations (Xue and Kanzaki, 2004, 2006, 2008; Xue, 2009) as well as Raman and IR studies (McMillan et al., 1993; Malfait, 2009) on the $\mathrm{SiO}_{2}-\mathrm{NaAlSiO}_{4}$ and $\mathrm{SiO}_{2}-\mathrm{NaAlSi}_{3} \mathrm{O}_{8}$ joins have assigned this band to T-OH vibrations. Malfait (2009) observed a negative shift of both the 900 and the $3600 \mathrm{~cm}^{-1}$ Raman bands accompanied by a negative shift with increasing pressure of the 4500 $\mathrm{cm}^{-1}$ band observed by FTIR. In HGG glasses, however, only the $3600 \mathrm{~cm}^{-1}$ band shifts whereas the $900 \mathrm{~cm}^{-1}$ band remains at a constant frequency.

The negative shift of the water combination band and the decrease in intensity of the $900 \mathrm{~cm}^{-1}$ band may thus record a weakening of the $\mathrm{O}-\mathrm{H}$ bond upon increasing pressure (Fig. 9c). The negative shift of the water combination band occurs in both the nearly anhydrous HGG0 glass, in which only $\mathrm{OH}$ units are expected, as well as in the hydrous HGG4 and HGG5 sets, where water is dissolved as molecular and hydroxyl species (Stolper, 1982). The almost constant frequency of the $900 \mathrm{~cm}^{-1}$ band could suggest that pressure does not induce significant changes on the possible $\mathrm{Si}-\mathrm{OH}$ and/or Al-OH linkages in the HGG glasses. According to this interpretation, the weakening of the $\mathrm{O}-\mathrm{H}$ bond during 
694 densification of the HGG haplogranite glasses would increase above a pressure threshold of $\sim 1.5$

$695 \mathrm{GPa}$. We propose that the $\mathrm{O}-\mathrm{H}$ weakening is related to increasing interaction of $\mathrm{H}$ with neighboring 696 oxygen and to progressive partitioning of the H-bond on several anions (Sharma et al., 1996; 1997).

697 If this interpretation is correct, our data suggest that the relaxation of the $\mathrm{O}-\mathrm{H}$ bond is independent 698 from and precedes the relaxation of the bulk glass structures. In other terms, relaxed O-H structures 699 can coexist with quenched unrelaxed bulk silicate glass structures. The observation that the negative 700 frequency shift of the $\mathrm{O}-\mathrm{H}$ stretching envelope is quenched in most glasses suggests that the $\mathrm{O}-\mathrm{H}$ 701 bond weakens during compression, but that this process does not represent the elastic part of the 702 densification process. Although Hui et al. (2009) proposed an increase of the $\mathrm{OH} / \mathrm{H}_{2} \mathrm{O}_{\mathrm{m}}$ ratio with 703 pressure, this is not consistent with the negative shift of the $3600 \mathrm{~cm}^{-1}$ band (Di Muro et al., 2006; 704 Fig. 12) and with the small increase in $\mathrm{V}^{*}{ }_{\mathrm{H} 2 \mathrm{O}}$ at the highest pressures of this study (Table 3).

\subsection{Effect of structural changes on melt physical properties}

The evolution with pressure of the density and viscosity of silicate melts relates to structural changes occurring upon densification of the silicate network (Kushiro, 1978). Allwardt et al. (2005, 2007) reported a nonlinear relationship of pressure and the increase in Al-coordination in depolymerized

711 glasses and concluded that increasing Al-coordination is an important component for densification, 712 especially at high densifications (>5\%). However, an Al NMR study of our anhydrous and hydrous 713 haplogranites do not show significant changes in Al-coordination with pressure to $3.5 \mathrm{GPa}$ 714 suggesting that changes in $\mathrm{Al}$ coordination do not play a major role in the densification of these 715 glasses in this pressure range (Malfait et al., 2012). Hence, in our haplogranitic glasses the compaction of the structure upon pressure increase is achieved by topological arrangements. These include the reduction of the average inter-tetrahedral bond angle (Figs. 9a, 13) and possibly a redistribution of ring sizes (Figs. 8, 13), as identified in our study and by previous authors (Mysen et al., 1983; Poe et al., 2001; Seifert et al., 1982; Sharma et al., 1979). Water addition favors a reorganization of the ring sizes and average T-O-T angles at low pressure, these show small variations with pressure increase. Compaction is in this case accommodated by a small distortion of the rings and possible reorganization of the $\mathrm{Al} / \mathrm{Si}$ rich domains. The viscosity of melts displays a more complex relation with pressure at high temperature: the viscosity of more polymerized melts decreases with increasing pressure but increases with pressure for depolymerized compositions (e.g., Kushiro, 1976; 1978a; 1978b; Kushiro et al., 1976; Scarfe et al., 1979; McMillan and Wilding, 2009). The negative pressure dependence of viscosity has been explained by progressive increase of 5-fold coordinated Si and Al in densified melts (Kushiro, 1976, McMillan and Wilding, 2009). In high temperature anhydrous systems, Bottinga and Richet (1995) 
observed a positive correlation of viscosity with both pressure and network modifier content. Ardia 730 et al. (2008) have shown that the viscosity of dry rhyolite melts decreases linearly with pressure at 731 high temperature $\left(\mathrm{T}>1000^{\circ} \mathrm{C}\right)$ whereas the viscosity of hydrous rhyolites decreases with pressure at 732 high temperature but increases at low temperatures close to Tg (Ardia et al., 2008; Hui et al. 2009). 733 Following Al NMR results on hydrous rhyolites that show a negligible increase in 5-fold coordinated 734 Al up to $3.5 \mathrm{GPa}$ (Malfait et al., 2012), we note that the anomalies in the pressure dependence of the 735 viscosity of hydrous rhyolites cannot be fully explained by Al coordination changes. These 736 anomalies could be interpreted as variations of the activation volume of viscosity (Va), representing 737 the volume requirement for local motion and structural rearrangement (Ardia et al., 2008). In 738 anhydrous glasses, the decrease in viscosity with pressure is larger in the low-pressure range with 739 respect to higher pressures (i.e. $\mathrm{d} \eta / \mathrm{dP}$ decreases mostly at 1.0-1.5 GPa) (Ardia et al., 2008). In 740 hydrous glasses, the viscosity increases with pressure and results in a positive $\mathrm{d} \eta / \mathrm{dP}$ (Hui et al., 741 2009). On the basis of our Raman results, we ascribe the changes of the pressure effect on viscosity 742 to an evolution of the densification mechanisms operating at different pressures.

743 On the basis of our spectral data, we propose that in hydrous compositions increasing pressure 744 triggers a reorganization of the Al- and Si-rich domains above 1.0-1.5 GPa. Malfait et al. (2012) only 745 reported a slight increase in $\mathrm{Al}$ coordination in hydrous glasses above $1.5 \mathrm{GPa}$ that would not be 746 detectable in our Raman spectra. It is therefore plausible that this reorganization could result from an increase in $\mathrm{Al}$ coordination, which in turn affects the observed decrease in the densification rate with pressure. At higher pressures than explored here, possible modification of the network ring sizes and angles becomes less favorable in hydrous glasses, the increase in $\mathrm{Al}$ coordination being a more likely process for further compaction of the structure.

We have inferred that the compaction of the hydrous rhyolite network is mainly achieved by a redistribution and homogenization of ring sizes and a decrease of the average intertetrahedral angle at pressures below $1.5 \mathrm{GPa}$, whereas above this pressure, the dominant densification mechanism is the redistribution of $\mathrm{Al} / \mathrm{Si}$ rich domains. The observed structural modifications are thus consistent with the increase of the activation energy of viscous flow for hydrous liquids with pressure through

\section{CONCLUSION}

The densification mechanisms of haplogranite glasses have been investigated as a function of water content and pressure using density measurements and Raman spectroscopy. The main conclusions are summarized in Fig. 13. Densities and derived molar volumes display a linear dependence on pressure for the nearly anhydrous glasses. The densities of hydrous glasses rapidly increase linearly 
up to $1.5 \mathrm{GPa}$ but the densification rate decreases above this pressure. Densification upon pressure increase is associated first with a slight decrease of the partial molar volume of water up to $1.0 \mathrm{GPa}$, followed by an increase above this pressure that correlates with the reported higher $\mathrm{H}_{2} \mathrm{O}_{\mathrm{m}} / \mathrm{OH}^{-}$ratio at high pressure. Almost anhydrous liquids accommodate the increase in compression by distortion of the silicate network, including namely changes in T-O-T angles and average ring sizes. Pressure increase leads to an increase of the ordering of the Si/Al domains in the network of the water-poor liquids. The effect of pressure on the viscosity of nearly anhydrous compositions is reduced at higher pressures by a reorganization of the network. Water dissolved into the glass structure reduces significantly the range of possible ring sizes. In the hydrous glasses, the increase in density is thus essentially accommodated by a reorganization of ring sizes to an average ring (i.e., 6-membered ring) without major variations on the average T-O-T angles.

Acknowledgements. This work was supported by grant TH-27/05-3 of ETH Zurich and by grant No. 2-77182.02 of the Swiss National Science Foundation. P. Ardia further thanks the "Doktorandenstipendium" of ETH Zurich for financial support. We also thank N. Métrich of the Pierre Süe laboratory (CEA, France) for substantial support and W.J. Malfait for discussion. The authors want to thank two anonymous reviewers and the AE Dr. Toplis for comments that helped to improve the manuscript.

\section{References:}

Acosta-Vigil, A., London, D., and Morgan VI, G. (2005) Contrasting interactions of sodium and potassium with $\mathrm{H}_{2} \mathrm{O}$ in haplogranitic liquids and glasses at $200 \mathrm{MPa}$ from hydration-diffusion experiments. Contributions to Mineralogy and Petrology 149(3), 276-287.

Aines, R., and Rossman, G. (1984) Water in minerals? A peak in the infrared. Journal of

Geophysical Research 89 4059-4071.

Allwardt, J. R. and Poe, B. T. and Stebbins, J. F. (2005). The effect of fictive temperature on Al coordination in high-pressure $(10 \mathrm{GPa})$ sodium aluminosilicate glasses. American Mineralogist 90 (8-9), 1453-1457.

Allwardt, J. R., Stebbins, J. F., Terasaki, H., Du, L. S., Frost, D. J., Withers, A. C., Hirschmann, M. M., Suzuki, A., and Ohtani, E. (2007). Effect of structural transitions on properties of highpressure silicate melts: Al-27 NMR, glass densities, and melt viscosities. American Mineralogist 92(7), 1093-1104.

Ardia, P., Giordano, D., and Schmidt, M.W. (2008). A model for the viscosity of rhyolite as a function of $\mathrm{H}_{2} \mathrm{O}$ content and pressure: A calibration based on centrifuge piston cylinder experiments. Geochimica et Cosmochimica Acta 72 6003-6023.

Behrens, H. and Schulze, F. (2003). Pressure dependence of melt viscosity in the system NaAlSi3O8-CaMgSi2O6. American Mineralogist 88 1351-1363.

Behrens, H. and Stuke, A. (2003). Quantification of H2O contents in silicate glasses using IR spectroscopy - a calibration based on hydrous glasses analyzed by Karl-Fischer titration. Glass Science and Technology 76(4) 176-189.

Behrens, H., Roux, J., Neuville, D., and Siemann, M. (2006). Quantification of dissolved $\mathrm{H}_{2} \mathrm{O}$ in silicate glasses using confocal microRaman spectroscopy. Chemical Geology 229(1-3) 96- 
112.

Bottinga, Y. and Richet, P., (1995). Silicate melt structural relaxation: Rheology, kinetics, and Adam-Gibbs theory. Geochimica et Cosmochimica Acta 59 2725-2731.

Brooker, M., Nielsen, O., Praestgaard E. (1988). Assessment of correction procedures for reduction of Raman spectra. Journal of Raman spectroscopy 19(2) 71-78.

Champagnon, B., Panczer, G., Chemarin, C., and Humbert-Labeaumaz, B. (1996). Raman study of quartz amorphization by shock pressure. Journal of non-crystalline solids 196(1-3) 221-226.

Champagnon, B., Martinet, C., Boudeulle, M., Vouagner, D., Coussa, C., Deschamps, T., and Grosvalet, L. (2008). High pressure elastic and plastic deformations of silica: In situ diamond anvil cell Raman experiments. Journal of Non-Crystalline Solids 354(2-9) 569-573.

Del Gaudio, P. and Behrens, H. (2009). An experimental study on the pressure dependence of viscosity in silicate melts. The Journal of Chemical Physics 131 1-14.

Di Muro, A., Villemant, B., Montagnac, G., Scaillet, B., and Reynard, B. (2006a). Quantification of water content and speciation in natural silicic glasses (phonolite, dacite, rhyolite) by confocal microRaman spectrometry. Geochimica et Cosmochimica Acta 70(11) 2868-2884.

Di Muro, A., Giordano, D., Villemant, B., Montagnac, G., Scaillet, B., and Romano, C. (2006b). Influence of composition and thermal history of volcanic glasses on water content as determined by micro-Raman spectrometry. Applied Geochemistry 21(5) 802-812.

Di Muro, A., Métrich, N., Mercier, M., Giordano, D., Massare, D., and Montagnac, G. (2009). Micro-Raman determination of iron redox state in dry natural glasses: Application to peralkaline rhyolites and basalts. Chemical Geology 259 78-88.

Dingwell, D. B. and Webb, S. L. (1990). Relaxation in Silicate Melts. European Journal of Mineralogy 2(4) 427-449.

Dingwell DB, Romano C, Hess KU (1996). The effect of water on the viscosity of a haplogranitic melt under P-T-X conditions relevant to silicic volcanism. Contrib. Mineral. Petrol. 124 1928.

Dixon, J.E., Stolper, E.M., Holloway, J.R (1995). An experimental study of water and carbon dioxide solubilities in mid ocean ridge basaltic liquids .1. Calibration and solubility models. $J$. Petrol., 36(6) 1607-1631.

Galeener, F. (1979). Band limits and the vibrational spectra of tetrahedral glasses. Physical Review $B, 19(8)$ 4292-4297.

Galeener, F. and Geissberger, A. (1983). Vibrational dynamics in ${ }^{30} \mathrm{Si}$-substituted vitreous $\mathrm{SiO}_{2}$. Physical Review B 27(10) 6199-6204.

Giordano, D and Nichols, ARL and Dingwell, DB (2005). Glass transition temperatures of natural hydrous melts: a relationship with shear viscosity and implications for the welding process. Chemical Geology 256(3) 78-88 203-215. J. Volcanol. Geotherm. Red. 142(1) 105-118.

Giordano, D., Russell, K., Dingwell, D.B. (2008a). Viscosity of magmatic liquids: a model. Earth and Planetary Science Letters 271 123-134.

Giordano, D., Potuzak, M, Romano, C and Dingwell, DB and Nowak, M (2008b). Viscosity and glass transition temperature of hydrous melts in the system $\mathrm{CaAl}_{2} \mathrm{Si}_{2} \mathrm{O}_{8}-\mathrm{CaMgSi}_{2} \mathrm{O}_{6}$. Chemical Geology 256(3) 78-88 203-215.

Gottsmann, J., Giordano, D., and Dingwell, D. (2002). Predicting shear viscosity during volcanic processes at the glass transition: a calorimetric calibration. Earth and Planetary Science Letters 198(3) 417-428.

Hess, K.-U. and Dingwell, D. (1996). Viscosities of hydrous leucogranitic melts: A non-Arrhenian model. American Mineralogist 81 1297-1300.

Hochella, M. F. and Brown, G. E. (1985). The Structures of Albite and Jadeite Composition Glasses Quenched from High-Pressure. Geochimica et Cosmochimica Acta 49(5) 1137-1142.

Holtz, F., Behrens, H., Dingwell, D., and Taylor, R. (1992). Water solubility in alumosilicate melts of haplogranite composition at 2 kbar Chemical Geology 96 289-302.

Hui. H, Zhang Y., Behrens H. (2008). Pressure dependence of the speciation of dissolved water in rhyolitic melts. Geochimica et Cosmochimica Acta 72 4756-4777. 
Hui, H. and Zhang, Y. and Xu, Z. and Del Gaudio, P. and Behrens, H. (2009). Pressure dependence of viscosity of rhyolitic melts. Geochimica et Cosmochimica Acta 73 3680-3693.

Kalampounias, A.G., Yannopoulos, S.N., and Papatheodorou, G.N. (2006) A high-temperature Raman spectroscopic investigation of the potassium tetrasilicate in glassy, supercooled, and liquid states: The Journal of Chemical Physics, 125 (16) 164502, doi: 10.1063/1.2360275.

Kohn, S. C., Dupree, R., and Smith, M. E. (1989). Proton environments and hydrogen-bonding in hydrous silicate-glasses from proton NMR. Nature 337 539-541.

Kohn, S. C., Dupree, R., and Mortuza, M. (1992). The interaction between water and aluminosilicate magmas. Chemical geology 96(3-4) 399-409.

Kushiro, I. (1976). Changes in Viscosity and Structure of Melt of $\mathrm{NaAlAi}_{2} \mathrm{O}_{6}$ Composition at highpressures. J. Geophys. Res. 81 6347-6350.

Kushiro, I. (1978). Viscosity and structural changes of Albite $\left(\mathrm{NaAlSi}_{3} \mathrm{O}_{8}\right)$ melt at high pressures. Earth and Planetary Science Letters 41 87-90.

Lange, R. A. and Carmichael, I. S. E. (1987). Densities of $\mathrm{Na}_{2} \mathrm{O}-\mathrm{K}_{2} \mathrm{O}-\mathrm{CaO}-\mathrm{MgO}-\mathrm{FeO}-\mathrm{Fe}_{2} \mathrm{O}_{3}-\mathrm{Al}_{2} \mathrm{O}_{3}-$ $\mathrm{TiO}_{2}-\mathrm{SiO}_{2}$ Liquids - New Measurements and Derived Partial Molar Properties. Geochimica et Cosmochimica Acta 51(11) 2931-2946.

Lange, R. A. and Carmichael, I. S. E. (1989). Ferric-Ferrous Equilibria in $\mathrm{Na}_{2} \mathrm{O}-\mathrm{FeO}-\mathrm{Fe}_{2} \mathrm{O}_{3}-\mathrm{SiO}_{2}$ Melts- Effects of Analytical Techniques on Derived Partial Molar Volumes. Geochimica et Cosmochimica Acta 53(9) 2195-2204.

Lee, S.K. , Cody, G.D., Fei, Y.W., Mysen, B.O. (2006). The effect of Na/Si on the structure of sodium silicate and aluminosilicate glasses quenched from melts at high pressure: A multinuclear (Al-27, Na-23, O-17) 1D and 2D solid-state NMR study. Chem.Geol. 229 (1-3) 162172.

Le Losq, C., Moretti, R.; Neuville, D. R. (2013). Speciation and amphoteric behaviour of water in aluminosilicate melts and glasses: high-temperature Raman spectroscopy and reaction equilibria. Eur. J. Mineral. (25) 777-790.

Lipinska-Kalita, K.E., Gramsch, S.A., Kalita, P.E., and Hemley, R.J. (2005) In situ Raman scattering studies of high-pressure stability and transformations in the matrix of a nanostructured glassceramic composite. Journal of Raman Spectroscopy 36 938-945.

Long, D.A. (1977). Raman spectroscopy. McGraw-Hill New-York, 204.

Long, D.A (2002). The Raman Effect: A Unified Treatment of the Theory of Raman Scattering by Molecules. Wiley.

Malfait W.J., Zakaznova-Herzog V.P., and Halter W.E. (2008) Quantitative Raman spectroscopy: speciation of sodium silicate glasses and melts. American Mineralogist 93 1505-1518.

Malfait, W. (2009). The $4500 \mathrm{~cm}^{-1}$ infrared absorption band in hydrous aluminosilicate glasses is a combination band of the fundamental ( $\mathrm{Si}, \mathrm{Al})-\mathrm{OH}$ and $\mathrm{O}-\mathrm{H}$ vibrations. American Mineralogist 94 849-852.

Malfait, W.J., Sanchez-Valle C., Ardia P., Médard E., Lerch P. (2011) Compositionally dependent compressibility of dissolved water in silicate glasses. American Mineralogist 96 1402-1409.

Malfait, W.J., Verel, R., Ardia, P, Sanchez-Valle, C. (2012) Aluminum coordination in rhyolite and andesite glasses and melts: effect of temperature, pressure, composition and water content. Geochimica et Cosmochimica Acta 77 11-26, doi.org/10.1016/j.gca.2011.11.011.

Malfait, W.J. and Sanchez-Valle, C. (2013) Effect of water and network connectivity on glass elasticity and melt fragility, Chem.Geol. doi:10.1016/j.chemgeo.2012.04.034

Matson, D., Sharma, S., and Philpotts, J. (1983). The structure of high-silica alkali-silicate glasses. A Raman spectroscopic investigation. Journal of non-crystalline solids 58(2-3) 323-352.

Matson, D., Sharma, S., Philpotts, J., (1986). Raman spectra of some tectosilicates and of glasses along the orthoclase-anorthite and nepheline-anorthite joins. American Mineralogist 71, 694704.

Maxwell, JC. (1867). On the dynamical theory of gases. Philosophical Transactions of the Royal Society of London, 157, 49-88.

McMillan, P. (1984). Structural studies of silicate glasses and melts; applications and limitations of 
Raman spectroscopy? American Mineralogist 69(7-8) 622-644.

McMillan, P. and Hess, A. (1990). Ab initio valence force field calculations for quartz. Physics and Chemistry of Minerals 17(2) 97-107.

McMillan, P. and Wolf, G. (1995). Vibrational spectroscopy of silicate liquids. Reviews in Mineralogy and Geochemistry 32(1), 247-315.

McMillan, P.F., Wilding, M.C. (2009). High pressure effects on liquid viscosity and glass transition behavior, polyamorphic phase transitions and structural properties of glasses and liquids. J. Non-Cryst. Sol. 355, 722-732.

McMillan, P., Piriou, B., and Navrotsky, A. (1982). A Raman spectroscopic study of glasses along the joins silica-calcium aluminate, silica-sodium aluminate, and silica-potassium aluminate. Geochimica et Cosmochimica Acta 46(11) 2021-2037.

McMillan, P., Wolf, G., and Poe, B. (1992). Vibrational spectroscopy of silicate liquids and glasses. Chemical Geology 96(3-4) 351-366.

McMillan, P., Poe, B., Stanton, T., and Remmele, R. (1993). A Raman spectroscopic study of H/D isotopically substituted hydrous aluminosilicate glasses. Physics and Chemistry of Minerals 19(7) 454-459.

McMillan, P., Poe, B., Gillet, P., Reynard, B., (1994). A study of SiO2 glass and supercooled liquid to $1950 \mathrm{~K}$ via high-temperature Raman spectroscopy. Geochimica et Cosmochimica $\mathbf{5 8} 3653$ 3664.

McMillan, P. and Wilding, M.C. (2009) High pressure effects on liquid viscosity and glass transition behavior, polyamorphic phase transitions and structural properties of glasses and liquids. $J$. of. Non-Crystalline Solids 355(10-12) 722-732.

Mercier, M., Muro, A. D., Giordano, D., Métrich, N., Lesne, P., Pichavant, M., Scaillet, B., Clocchiatti, R., and Montagnac, G. (2009). Influence of glass polymerisation and oxidation on micro-raman water analysis in alumino-silicate glasses. Geochimica et Cosmochimica Acta 73(1) 197-217.

Morizet Y., Nichols A.R.L., Kohn C., Brooker RA., Dingwell, D.B. (2007). The influence of $\mathrm{H}_{2} \mathrm{O}$ and $\mathrm{CO}_{2}$ on the glass transition temperature: insights into the effects of volatiles on magma viscosity. Eur. J. Mineral. 19(5) 657-669. DOI: 10.1127/0935-1221/2007/0019-1751

Moynihan C. T., Easteal A. J., Wilder J. and Tucker J. (1976) Dependence of the glass transition temperature on heating and cooling rate. J. Phys. Chem. 78, 2673-2677.

Moynihan, C.T. (1995). Structural relaxation and the glass transition. Review in Mineralogy 32 1-19.

Mysen, B. O., Virgo, D., and Scarfe, C. M. (1980a). Relations between the Anionic Structure and Viscosity of Silicate Melts - a Raman-Spectroscopic Study. American Mineralogist 65(7-8) 690-710.

Mysen, B. O., Virgo, D., Harrison, W. J., and Scarfe, C. M. (1980b). Solubility Mechanisms of $\mathrm{H}_{2} \mathrm{O}$ in Silicate Melts at High-Pressures and Temperatures - a Raman-Spectroscopic Study. American Mineralogist 65(9-10) 900-914.

Mysen, B.O., Finger, L.W., Virgo, D., and Seifert, F.A (1982) Curve-fitting of Raman spectra of silicate glasses. American Mineralogist. 67. 686-695.

Mysen, B. O., Virgo, D., Danckwerth, P., Seifert, F. A., and Kushiro, I. (1983). Influence of Pressure on the Structure of Melts on the Joins NaAlO2-SiO2, CaAl2O4-SiO2, and MgAl2O4-SiO2. Neues Jahrbuch Fur Mineralogie-Abhandlungen, 147(3), 281-303.

Mysen, B. O. and Virgo, D. (1986). Volatiles in silicate melts at high pressure and temperature. II: Water in melts along the join $\mathrm{NaAlO} 2-\mathrm{SiO} 2$ and a comparison of solubility mechanisms of water and fluorine. Chemical Geology 57(3-4) 333-358.

Mysen, B. O. (1988). Structure and proprieties of Silicate Melts. Elsevier

Mysen, B.O. and Frantz, J. (1993). Structure and properties of alkali silicate melts at magmatic temperatures. European Journal of Mineralogy 5(3) 393.

Mysen, B.O., and Frantz, J. (1994) Silicate melts at magmatic temperatures: in-situ structure determination to $1651^{\circ} \mathrm{C}$ and effect of temperature and bulk composition on the mixing behavior of structural units. Contributions to Mineralogy and Petrology 117 1-14. 
Mysen, B.O. (1999) Structure and properties of magmatic liquids: From haplobasalt to haploandesite. Geochimica et Cosmochimica Acta, 63 95-112.

Mysen, B.O., Toplis, M.J. (2007). Structural behavior of $\mathrm{Al}^{3+}$ in peralkaline, metaluminous, and peraluminous silicate melts and glasses at ambient pressure. American Mineralogist 92 933946.

Neuville, D. and Mysen, B. (1996). Role of aluminum in the silicate network: In situ, hightemperature study of glasses and melts on the join $\mathrm{SiO}_{2}-\mathrm{NaAlO}_{2}$. Geochimica et Cosmochimica Acta 60(10) 1727-1737.

Neuville, D.R., Cormier, L., Montouillout, V., Florian, P., Millot, F., Rifflet, J.C., and Massiot, D., (2008) Amorphous materials: Properties, structure, and durability: Structure of Mg- and $\mathrm{Mg} / \mathrm{Ca}$ aluminosilicate glasses: 27Al NMR and Raman spectroscopy investigations. American Mineralogist 93 1721-1731.

Nielsen, O., Mortensen, A., Yarwood, J., and Shelley, V. (1996). Use of isotope effects in studies of intermolecular interactions by Raman spectroscopy. Journal of Molecular Structure 378(1) $1-9$.

Ochs, F.A. III and Lange, R.A. (1999). The density of hydrous magmatic liquids. Science 283 13141317.

Okuno, M., Iwatsuki, H., and Matsumoto, T. (1996). Structural analysis of an obsidian by X-ray diffraction method. European Journal of Mineralogy 8(6) 1257-1264.

Okuno, M., Reynard, B., Shimada, Y., Syono, Y., and Willaime, C. (1999). A Raman spectroscopic study of shock-wave densification of vitreous silica. Physics and Chemistry of Minerals 26(4), 304-311.

Pasquarello, A. and Car, R. (1998). Identification of Raman Defect Lines as Signatures of Ring Structures in Vitreous Silica. Physical Review Letters 80(23) 5145-5147.

Poe, B. T., Romano, C., Zotov, N., Cibin, G., and Marcelli, A. (2001). Compression mechanisms in aluminosilicate melts: Raman and XANES spectroscopy of glasses quenched from pressures up to $10 \mathrm{GPa}$. Chemical Geology 174(1-3) 21-31.

Poe, B. T., Romano, C., Liebske, C., Rubie, D. C., Terasaki, H., Suzuki, A., and Funakoshi, K. (2006). High-temperature viscosity measurements of hydrous albite liquid using in-situ falling-sphere viscometry at 2.5 GPa. Chemical Geology 229(1-3) 2-9.

Popel, P., Stankus, S., Mozgovoy, A., Khairulin, R., Pokrasin, M., Yagodin, D., Konstantinova, N., Borisenko, A., and Guzachev, M. (2011) Physical properties of heavy liquid-metal coolants in a wide temperature range. EPJ Web of Conferences 1501014.

Reynard, B., Okuno, M., Shimada, Y., Syono, Y., and Willaime, C. (1999). A Raman spectroscopic study of shock-wave densification of anorthite $\left(\mathrm{CaAl}_{2} \mathrm{Si}_{2} \mathrm{O}_{8}\right)$ glass. Physics and Chemistry of Minerals 26(6) 432-436.

Richet, P., Whittington, A., Holtz, F., Behrens, H., Ohlhorst, S., and Wilke, M. (2000). Water and the density of silicate glasses. Contributions to Mineralogy and Petrology 138(4) 337-347.

Romano, C., Poe, B., Mincione, V., Hess, K., and Dingwell, D. (2001). The viscosities of dry and hydrous $\mathrm{XAlSi}_{3} \mathrm{O}_{8}(\mathrm{X}=\mathrm{Li}, \mathrm{Na}, \mathrm{K}, \mathrm{Ca} 0.5, \mathrm{Mg} 0.5)$ melts. Chemical Geology 174(1-3), 115132.

Ruiz, F., Martìnez, J., and González-Hernández, J. (2002). A simple model to analyze vibrationally decoupled modes on $\mathrm{SiO}_{2}$ glasses. Journal of Molecular Structure 641(2-3) 243-250.

Scherer, G. (1984). Use of the Adam-Gibbs equation in the analysis of structural relaxation. Journal of the American Ceramic Society 67(7), 504-511.

Schulze, F. and Behrens, H. and Holtz, F. and Roux, J. and Johannes, W. (1996). The influence of $\mathrm{H}_{2} \mathrm{O}$ on the viscosity of haplogranitic melt. American Mineralogist 81 1155-1165.

Seifert, F., Mysen, B., Virgo, D., (1981). Structural Similarity of Glasses and Melts Relevant to Petrological Processes. Geochimica et Cosmochimica Acta 45 1879-1884.

Seifert, F., Mysen, B., and Virgo, D. (1982). Three-dimensional network structure of quenched melts (glass) in the systems $\mathrm{SiO}_{2}-\mathrm{NaAlO}_{2}, \quad \mathrm{SiO}_{2}-\mathrm{CaAl}_{2} \mathrm{O}_{2}$ and $\mathrm{SiO}_{2}-\mathrm{MgAl}_{2} \mathrm{O}_{4}$. American Mineralogist 67(7-8) 696-717. 
1014

1015

1016

1017

1018

1019

1020

1021

1022

1023

1024

1025

1026

1027

1028

1029

1030

1031

1032

1033

1034

1035

1036

1037

1038

1039

1040

1041

1042

1043

1044

1045

1046

1047

1048

1049

1050

1051

1052

1053

1054

1055

1056

1057

1058

1059

1060

1061

1062

1063

1064

1065

Seifert, F. A., Mysen, B. O., and Virgo, D. (1983). Raman study of densified vitreous silica. Physics and Chemistry of Glasses 24 141-145.

Sharma, S. K., Virgo, D., and Mysen, B. O. (1979). Raman Study of the Coordination of Aluminum in Jadeite Melts as a Function of Pressure. American Mineralogist 64(7-8) 779-787.

Sharma, S., Matson, D., Philpotts, J., and Roush, T. (1984). Raman study of the structure of glasses along the join $\mathrm{SiO}_{2}-\mathrm{GeO}_{2}$. J. Non-Cryst. Solids 68(1) 99-114.

Sharma, S., Wang, Z., and van der Laan, S. (1996). Raman Spectroscopy of Oxide Glasses at High Pressure and High Temperature. J. Raman Spectrosc., 27 739-746.

Sharma, S., Cooney, T., and Wang, Z. (1997). Raman band assignments of silicate and germanate glasses using high-pressure and high-temperature spectral data. J. Raman Spectrosc. 28(9) 697-709.

Shaw, H. (1963). Obsidian- $\mathrm{H}_{2} \mathrm{O}$ Viscosities at 1000 and 2000 Bars in the temperature range 700 to $900^{\circ} \mathrm{C}$. Journal of Geophysical Research $\mathbf{6 8} 6337-6343$.

Shimoda, K., Okuno, M., Syono, Y., Kikuchi, M., Fukuoka, K., Koyano, M., and Katayama, S. (2004). Structural evolutions of an obsidian and its fused glass by shock-wave compression. Physics and Chemistry of Minerals 31(8) 532-542.

Sipp, A. and Richet, P. (2002). Equivalence of volume, enthalpy and viscosity relaxation kinetics in glass-forming silicate liquids. Journal of Non-Crystalline Solids 298 202-212.

Stevenson, R.J., Dingwell, D.B., Webb, S.L., Bagdassarov, N.S. (1995). The equivalence of enthalpy and shear stress relaxation in rhyolitic obsidian and quantification of the liquid-glass transition in volcanic processes. J. Volcanol. Geotherm. Res. 68, 297- 306.

Stolper, E. (1982) The speciation of water in silicate melts. Geochimica et Cosmochimica Acta 46(12) 2609-2620.

Suzuki, A., Ohtani, E., Funakoshi, K., Terasaki, H., and Kubo, T. (2002). Viscosity of albite melt at high pressure and high temperature. Physics and Chemistry of Minerals 29 159-165.

Thao To, T., Bougeard, D , and Smirnov, KS. (2008) Molecular dynamics study of the vibrational pattern of ring structures in the Raman spectra of vitreous silica. J. Raman Spectrosc. 2008; 39 1869-1877.

Taylor, M., Brown, G.E., Jr, (1979). Structure of mineral glasses-II. The $\mathrm{SiO}_{2}-\mathrm{NaAlSiO}_{4}$ join. Geochimica et Cosmochimica Acta 43 1467-1473.

Tinker, D., Lesher, C., and Hutcheon, I. (2003), Self-diffusion of Si and O in diopside-anorthite melt at high pressures. Geochimica et Cosmochimica Acta 67 133-142.

Toplis, M., Dingwell, D., Lenci, T. (1997). Peraluminous viscosity maxima in $\mathrm{Na}_{2} \mathrm{O}-\mathrm{Al}_{2} \mathrm{O}_{3}-\mathrm{SiO}_{2}$ liquids: The role of triclusters in tectosilicate melts. Geochimica et Cosmochimica Acta $\mathbf{6 1}$ 2605-2612.

Toplis, M.J., Gottsmann, J., Knoche, R., Dingwell, D.B. (2001). Heat capacities of haplogranitic glasses and liquids. Geochimica et Cosmochimica Acta 65 1985-2001.

Withers, A. and Behrens, H. (1999). Temperature-induced changes in the NIR spectra of hydrous albitic and rhyolitic glasses between 300 and 100 K. Physics and Chemistry of Minerals 27 $119-132$.

Xue X. and KanzakiM. (2004) Dissolution mechanisms of water in depolymerized silicate melts: constraints from $1 \mathrm{H}$ and ${ }^{29} \mathrm{Si}$ NMR spectroscopy and ab initio calculations. Geochimica et Cosmochimica Acta $685027-5057$.

Xue X. and Kanzaki M. (2006) Depolymerization effect of water in aluminosilicate glasses: direct evidence from 1H-27Al heteronuclear correlation, NMR. American Mineralogist 911922 1926.

Xue, X. and Kanzaki, (2008). M. Structure of hydrous aluminosilicate glasses along the diopsideanorthite join: A comprehensive one-and two-dimensional $1 \mathrm{H}$ and 27Al NMR study. Geochimica et Cosmochimica Acta 72 2331-2348.

Xue, X. (2009) Water speciation in hydrous silicate and aluminosilicate glasses: Direct evidence from 29Si-1H and 27Al-1H double-resonance NMR. American Mineralogist 94 395-398.

Zajacz, Z., Halter, W., Malfait, W., Bachmann, O., Bodnar, R., Hirschmann, M., Mandeville, C., 
Morizet, Y., Muentener, O., Ulmer, P., and Webster, J. (2005). A composition-independent quantitative determination of the water content in silicate glasses and silicate melt inclusions by confocal Raman spectroscopy. Contribution to Mineral Petrology 150(6) 631-642.

Zhang, Y.X., Xu, Z.J., and Liu, Y. (2003). Viscosity of hydrous rhyolitic melts inferred from kinetic experiments, and a new viscosity model. American Mineralogist 88 1741-1752.

Zotov, N., Yanev, Y., Epelbaum, M., and Konstantinov, L. (1992) Effect of Water on the Structure of Rhyolite Glasses - X-Ray-Diffraction and Raman-Spectroscopy Studies. Journal of NonCrystalline Solids 142 234-246.

Zotov N. and Keppler H. (1998) The influence of water on the structure of hydrous sodium tetrasilicate glasses. American Mineralogist 83 823-834.

Zotov, N. (2003) Structure of natural volcanic glasses: diffraction versus spectroscopic perspective. Journal of Non-Crystalline Solids 323 1-6. 
1081 Fig. 1: Strategy for the treatment of Raman spectra in the spectral domain related to vibrations of the 1082 aluminosilicate framework: a) subtraction of the baseline (dotted) from the raw spectra; b) Long 1083 correction using Eq. 3, and c) normalization with respect to the highest peak of the LF envelope, smoothing of the data by using the Loess equation (3\%) (line in c). See details in the text.

Fig. 2: Example of cubic baseline subtraction to the Raman spectral domain related to $\mathrm{OH}$-stretching vibration (here the spectrum of the HGG5 glass at $0.5 \mathrm{GPa}$ ) and subsequent smoothing (grey line; Loess equation $3 \%$ ).

Fig. 3: a) Measured densities vs. quench pressure for the synthesized HGG glasses and comparison with measured densities for dry albite glasses (Kushiro, 1976) and calculated densities for dry rhyolites quenched at $0.5 \mathrm{GPa}$ using the pressure release technique (Withers and Behrens, 1999). Lines are guidelines and the arrow indicates the data point with the anomalously low density for HGG4 at 2.5 GPa discussed in the text. This glass is not considered for further discussion. b) Measured densities vs. water content for HGG and rhyolitic glasses at various pressures. The rhyolite glasses of Withers and Behrens (1999) were obtained by rapid quench $(>100 \%$ s) with pressure release from $0.3 \mathrm{GPa}$ (black stars) and by slow cooling (ca. 100-150\% $/ \mathrm{min}$ ) from $0.5 \mathrm{GPa}$ (white stars). Errors of density measurement are smaller than symbol size.

Fig. 4: Molar volume of the haplogranitic matrix vs. total dissolved water in molar fraction (calculated as molecular water) at various pressures. Symbols are the calculated values for HGG at the corresponding pressure. Lines are fits at each pressure $(0.5,1.0,1.5$, and $2.5 \mathrm{GPa})$ assuming ideal mixing volumes. The fit lines yield the partial molar volume of the dry silicate $\left(\mathrm{V}_{\text {sil }}\right)$ and of water $\left(\mathrm{V}^{*}{ }_{\mathrm{H} 2 \mathrm{O}}\right)$ as they intercept with the y-axis at 0 and 1 , respectively (Table 3$)$. Errors are calculated by propagating experimental errors in the density measurements.

Fig. 5: Unpolarized (black), parallel (VV, grey above), and perpendicular (VH, grey lower plot) polarized spectra of the nearly anhydrous composition at $1 \mathrm{~atm}$ (a), and (b) of the HGG3 glass with $2.7 \mathrm{wt} \% \mathrm{H}_{2} \mathrm{O}$, synthesized at $0.5 \mathrm{GPa}$. Spectra are VV-polarized when the electric vectors of the incoming and scattered light are parallel and VH-polarized when they are perpendicular. Spectra 1112 the frequency of the vibrational bands whereas the grey numbers in italic indicate experimental 1113 frequencies values of bands in the polarized spectra (Table 3). The difference in recorded intensity 
1114 between (a) and (b) is due to shorter acquisition time for the hydrous sample to avoid exsolution of $1115 \mathrm{H}_{2} \mathrm{O}$.

1117 Fig. 6: Deconvolution strategy for the HF envelope, normalized to the peak high of the LF envelope 1118 (Fig. 1), here applied to all the synthesized glasses at $0.5 \mathrm{GPa}$. Six deconvolution bands with fixed 1119 position and shape (width/intensity ratio, highlighted by the grey zones), imposed by the 1120 deconvolution of the polarized spectra (Fig. 5), are used to treat the HF envelope. The "PeakFit" 1121 software is used to optimize the $r^{2}$ value (min. 0.997) predefining the 6 deconvolution bands marked 1122 by the representative frequencies (see text). Generated line is created by the deconvolution strategy.

1124 Fig. 7: Treated and smoothed spectra of the nearly anhydrous HGG0 glasses synthesized at different 1125 pressures. The dotted lines represent the frequencies of interest discussed in the text which values are 1126 given in italic. The most intense envelope (LF) shifts from 461 at room conditions $\left(469 \mathrm{~cm}^{-1}\right.$ at 0.5 $1127 \mathrm{GPa})$ to $493 \pm 5 \mathrm{~cm}^{-1}$, the HF envelope displays a slight negative shift from 1141 to $1133 \mathrm{~cm}^{-1}( \pm 10$

$1128 \mathrm{~cm}^{-1}$ ), and the main water band is negatively shifted from $3447 \pm 10 \mathrm{~cm}^{-1}$ to $3424 \pm 10 \mathrm{~cm}^{-1}$. The four 1129 different spectral region discussed in the text are shown with different background colors.

1131 Fig. 8: Full Width at Half Maximum (FWHM*) of the LF envelope (non smoothed) vs. pressure of 1132 glass synthesis. The width is measures at the half-height of the LF envelope, without any specific 1133 deconvolution of the envelope.

1135 Fig. 9: Experimental frequencies and intensities of the normalized spectra (with Long correction, 1136 without smoothing) previous deconvolution vs. pressure. (a) position of the LF main envelope and of 1137 the D1 defect band only for HGG0 (crosses); (b) normalized intensity of the D2 band; (c) normalized 1138 intensity of the $900 \mathrm{~cm}^{-1}$ band for the hydrous glasses; (d) Frequency of the HF envelope; and (e) 1139 intensity of the HF envelope. Error on the frequency is $\pm 5 \mathrm{~cm}^{-1}$ for the LF spectral region and \pm 10 $1140 \mathrm{~cm}^{-1}$ for $\mathrm{HF}$ region. The error for the intensities is calculated considering the variation of the 1141 intensities in the frequency errors.

1143 Fig. 10: Spectral evolution of the HF envelope in terms of area variation of the deconvoluted bands 1144 (Fig. 6) vs. pressure in \% deviation from the reference value of the glasses of the same composition 1145 synthesized at $0.5 \mathrm{GPa}$, here (a) for the nearly anhydrous glasses. (b) Deconvoluted band at $1045 \mathrm{~cm}^{-}$ $1146{ }^{1}$, NBO structure, for all the different glass compositions vs. pressure. 
1148 Fig. 11: Treated and smoothed spectra of all the investigated glasses synthesized at 0.5 GPa, with 1149 from the bottom to the top the increasing bulk water content. The vertical dotted lines represent the 1150 frequencies of interest discussed in the text, roman numbers in quotation marks depicting band 1151 labels, italic numbers accurate frequencies, both used in the text.

1153 Fig. 12: Treated and smoothed spectra of the hydrous HGG glasses at different pressures. Vertical 1154 dotted lines identify the frequency values of the Raman bands of interest described in the text: LF 1155 main envelope $\left(480 \pm 5 \mathrm{~cm}^{-1}\right)$ and the shoulder formed by the D2 defect band $\left(590 \pm 5 \mathrm{~cm}^{-1}\right)$, the 1156 broad MF envelope at $800 \mathrm{~cm}^{-1}$, the $\mathrm{HF}$ envelope with the band at $900 \mathrm{~cm}^{-1}$, and the OH-stretching 1157 region at high frequencies. The numbers in italic are the effective experimental frequencies picked 1158 from the spectra (Table 5, error \pm 5 for $\mathrm{LF}, \pm 10 \mathrm{~cm}^{-1}$ for HF). Note the different $\mathrm{x}$-axis scale of the 1159 low and high frequency sides.

Fig. 13: Schematic representation of the effect of pressure on the physical properties of water-poor 1162 (left) and water-rich (right) glasses. A) Viscosity $\eta$ and $\mathrm{T}_{\mathrm{g}}$, B) density, C) evolution of the T-O-T 1163 mean angle, D) Al-coordination (Malfait et al., 2012); E) ring population. At the bottom (F), the 1164 pressure effect on the Raman water band, where the intensities of the water-poor Raman spectra 1165 (bottom left) were increased to highlight the band shifts. Viscosity is expressed as the value at $\mathrm{T}_{\mathrm{ae}}$ 1166 close to the $\mathrm{T}_{\mathrm{g}}$. 
Table 1: Calculated quench temperature at viscosities of $10^{9.3}$ and $10^{12} \mathrm{~Pa} \mathrm{~s}$.

\begin{tabular}{|c|c|c|c|c|c|c|}
\hline & & model: & Ardia et al., 200 & 8 Hui et al., 2009 & Ardia et al., 20 & Hui et al., 2009 \\
\hline sample & $\mathrm{H}_{2} \mathrm{O}(\mathrm{wt} \%)$ & $\mathrm{P}(\mathrm{GPa})$ & $T_{a e}\left({ }^{\circ} \mathrm{C}\right)$ & $=10^{9.3} \mathrm{Pas}$ & $T_{a e}\left({ }^{\circ} \mathrm{C}\right)$ & $=10^{12} \mathrm{Pas}$ \\
\hline HGG0 & 0.15 & $1 \mathrm{~atm}$ & 895 & 879 & 749 & 710 \\
\hline & & 0.5 & 873 & 874 & 731 & 714 \\
\hline & & 1.0 & 852 & 859 & 713 & 700 \\
\hline & & 1.5 & 830 & 838 & 695 & 675 \\
\hline & & 2.0 & 808 & 817 & 677 & 655 \\
\hline & & 2.5 & 786 & 798 & 659 & 640 \\
\hline$\overline{\text { HGG3 }}$ & 2.69 & 0.5 & 500 & 540 & 365 & 438 \\
\hline & & 1.0 & 478 & 545 & 347 & 444 \\
\hline & & 1.5 & 456 & 551 & 329 & 452 \\
\hline & & 2.0 & 435 & 560 & 311 & 463 \\
\hline & & 2.5 & 413 & 571 & 293 & 470 \\
\hline HGG4 & 3.63 & 0.5 & 440 & 502 & 309 & 405 \\
\hline & & 1.0 & 419 & 504 & 290 & 409 \\
\hline & & 1.5 & 397 & 509 & 272 & 416 \\
\hline & & 2.0 & 375 & 517 & 254 & 425 \\
\hline & & 2.5 & 353 & 526 & 236 & 436 \\
\hline HGG5 & 5.24 & 0.5 & 362 & 454 & 234 & 364 \\
\hline & & 1.0 & 340 & 453 & 216 & 365 \\
\hline & & 1.5 & 318 & 456 & 198 & 370 \\
\hline & & 2.0 & 297 & 462 & 180 & 377 \\
\hline & & 2.5 & 275 & 469 & 162 & 387 \\
\hline
\end{tabular}


Table 2: density and molar volume of HGG glasses at increasing water contents and quench pressures and calculated density at vario

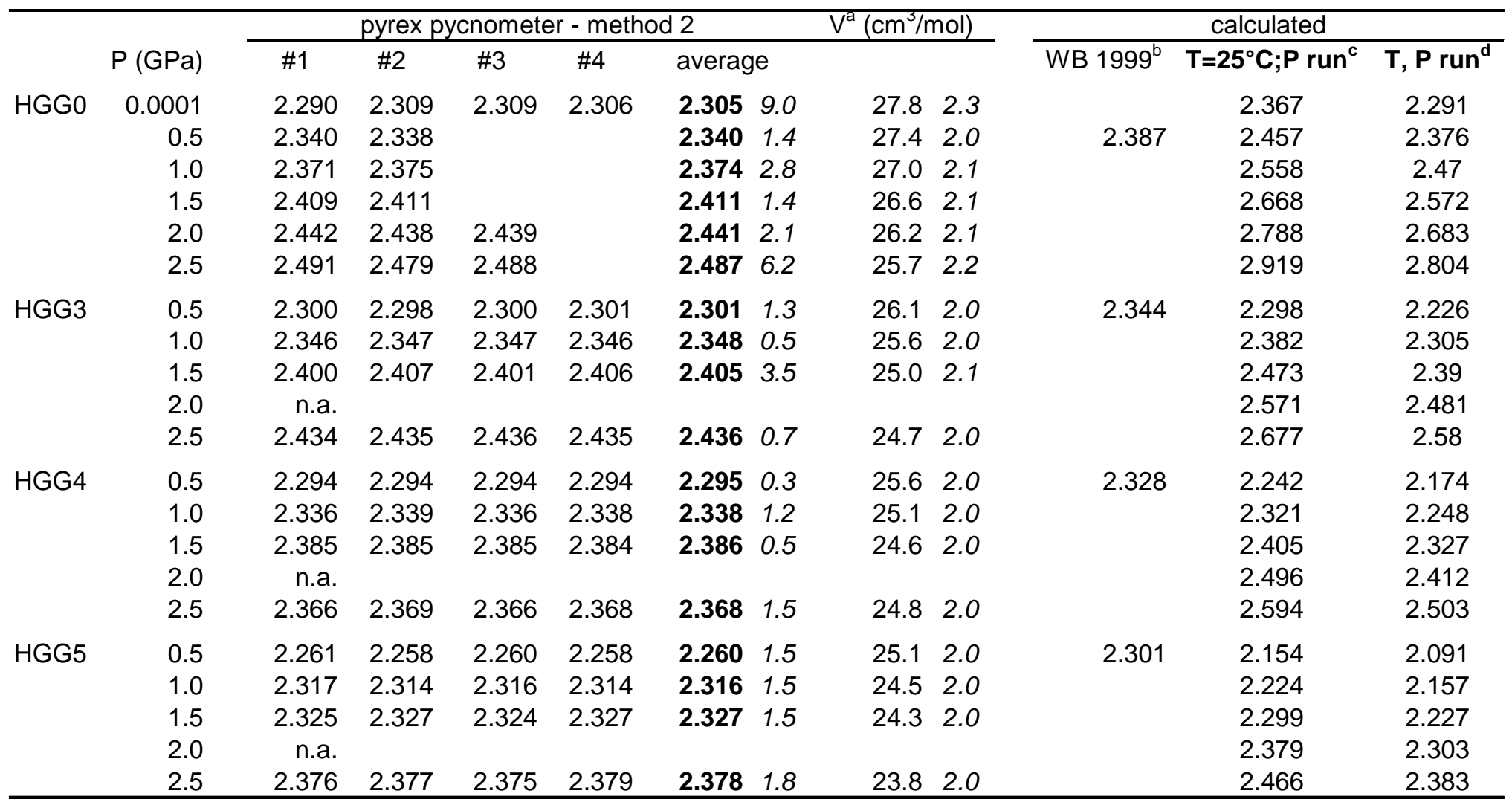

errors are given in italic on the last digit number.

a) molar volume calculated as described by Richet et al. (2000) (assuming water as $\mathrm{H}_{2} \mathrm{O}$ ).

b) calculated as indicated by Withers and Behrens (1999) for rhyolitic glasses quenched at $0.5 \mathrm{GPa}$ with a T ramp of $200 \% \mathrm{~min}$.

c, and d) calculated following Lange and coworkers (Lange and Carmichael, 1987; Lange, 1996; 1997; Ochs and Lange, 1999). 
Table 4: Deconvolution and depolarization ratios of HF bands.

\begin{tabular}{|c|c|c|c|c|c|c|c|c|c|c|}
\hline \multirow{2}{*}{\multicolumn{6}{|c|}{ HGG0; 0.15 wt $\% \mathrm{H}_{2} \mathrm{O}$}} & \multirow{2}{*}{\multicolumn{5}{|c|}{ HGG3; 2.69 wt $\% \mathrm{H}_{2} \mathrm{O}$}} \\
\hline & & & & & & & & & & \\
\hline Peak & Center $^{\mathrm{a}}$ & FWHM & $\%$ Area & dep ratio & & Center $^{\mathrm{a}}$ & FWHM & $\%$ Area & dep ratio & \\
\hline 1 & 801 & 94 & 24.4 & 0.179 & faint pol. & 799 & 94 & 23.9 & 0.296 & dep. \\
\hline 2 & 904 & 61 & 4.8 & 0.151 & faint pol. & 907 & 87 & 18 & 0.19 & faint pol. \\
\hline 3 & 980 & 95 & 10.2 & 0.147 & faint pol. & 982 & 92 & 10.6 & 0.552 & dep. \\
\hline 4 & 1059 & 97 & 21.5 & 0.227 & faint pol. & 1044 & 90 & 12.4 & 0.476 & dep. \\
\hline 5 & 1133 & 82 & 24.5 & 0.082 & pol. & 1126 & 106 & 25 & 0.204 & faint pol. \\
\hline \multirow[t]{2}{*}{6} & 1191 & 77 & 14.6 & 0.082 & pol. & 1187 & 98 & 10.1 & 0.174 & faint pol. \\
\hline & VH & & & & & VH & & & & \\
\hline 1 & 796 & 84 & 24.8 & & & 794 & 84 & 19.9 & & \\
\hline 2 & 917 & 97 & 7.3 & & & 902 & 83 & 10.3 & & \\
\hline 3 & 977 & 85 & 8.5 & & & 977 & 92 & 18.5 & & \\
\hline 4 & 1040 & 101 & 32.3 & & & 1047 & 80 & 16.6 & & \\
\hline 5 & 1140 & 113 & 17.7 & & & 1140 & 126 & 19.2 & & \\
\hline 6 & 1186 & 95 & 9.4 & & & 1197 & 274 & 15.5 & & \\
\hline
\end{tabular}

a) position of the band in $\mathrm{cm}^{-1}\left(+/-10 \mathrm{~cm}^{-1}\right)$. 
Table 5: Raman band position of the HGG glasses at increasing water contents and quench pressures.

\begin{tabular}{|c|c|c|c|c|c|c|c|c|}
\hline & \multirow[b]{2}{*}{$\mathrm{P}(\mathrm{GPa})$} & \multicolumn{3}{|c|}{ LF region $\left( \pm 5 \mathrm{~cm}^{-1}\right)$} & \multicolumn{2}{|c|}{ HF region $\left( \pm 10 \mathrm{~cm}^{-1}\right)$} & \multicolumn{2}{|c|}{ water band $\left( \pm 10 \mathrm{~cm}^{-1}\right)$} \\
\hline & & LF band & $\mathrm{D} 2$ & D2 - smooth $^{\mathrm{b}}$ & 1050 shoulder & HF band & peak pos. & $\mathrm{H}_{2} \mathrm{O}$ tot $^{\mathrm{a}}$ \\
\hline \multirow[t]{6}{*}{ HGG0 } & 0.0001 & 461 & 595 & 591 & 1052 & 1130 & $3506^{\mathrm{c}}$ & 0.15 \\
\hline & 0.5 & 469 & 596 & 590 & 1049 & 1141 & $3447^{\mathrm{c}}$ & 0.15 \\
\hline & 1.0 & 468 & 594 & 590 & 1055 & 1132 & $3459^{c}$ & 0.13 \\
\hline & 1.5 & 474 & 596 & 590 & 1047 & 1129 & $3434^{\mathrm{c}}$ & \\
\hline & 2.0 & 482 & 596 & 590 & 1051 & 1135 & $3421^{\mathrm{c}}$ & \\
\hline & 2.5 & 493 & 594 & 590 & 1053 & 1133 & $3424^{\mathrm{c}}$ & \\
\hline \multirow[t]{5}{*}{ HGG3 } & 0.5 & 485 & 583 & 590 & 1056 & 1138 & 3577 & \\
\hline & 1.0 & 483 & 581 & 590 & 1047 & 1143 & 3581 & \\
\hline & 1.5 & 486 & 578 & 590 & 1044 & 1133 & 3568 & \\
\hline & 2.0 & 482 & 581 & 590 & 1038 & 1126 & 3573 & \\
\hline & 2.5 & 482 & 581 & 590 & 1053 & 1134 & 3575 & \\
\hline \multirow[t]{5}{*}{ HGG4 } & 0.5 & 488 & 574 & 590 & 1053 & 1138 & 3580 & \\
\hline & 1.0 & 483 & 576 & 593 & 1049 & 1134 & 3578 & \\
\hline & 1.5 & 488 & & 590 & 1048 & 1133 & 3577 & \\
\hline & 2.0 & 486 & & 590 & 1053 & 1132 & 3570 & \\
\hline & $2.5^{\mathrm{d}}$ & 486 & & 590 & 1048 & 1124 & 3563 & \\
\hline \multirow[t]{5}{*}{ HGG5 } & 0.5 & 483 & & 584 & 1057 & 1138 & 3574 & \\
\hline & 1.0 & 485 & & 587 & 1057 & 1130 & 3570 & \\
\hline & 1.5 & 483 & & 590 & 1053 & 1132 & 3567 & \\
\hline & 2.0 & 488 & & 590 & 1049 & 1129 & 3564 & \\
\hline & 2.5 & 486 & & 590 & 1036 & 1121 & 3557 & \\
\hline
\end{tabular}

a) water content calculated by internal calibration, see di Muro et al. (2006a)

b) D2 frequency after smoothing

c) highest peak after smoothing, related error is $\pm 8 \mathrm{~cm}^{-1}$.

d) not considered for the discussion. 
Table 3: Molar volume of dry silicate and partial molar volume of molecular water

\begin{tabular}{lccccc}
\hline & $\mathrm{P}(\mathrm{GPa})$ & $\mathrm{V}_{\text {sil }}$ & \multicolumn{3}{c}{$\mathrm{V}^{*}{ }_{\mathrm{H} 2 \mathrm{O}}$} \\
\hline HGG at P: & & & & & \\
& 0.50 & 27.42 & 22 & 12.82 & 100 \\
& 1.00 & 27.04 & 20 & 11.23 & 100 \\
& 1.50 & 26.49 & 33 & 12.17 & 100 \\
& 2.50 & 25.79 & 30 & 13.74 & 100 \\
\hline
\end{tabular}

literature data:

\begin{tabular}{lccrrr}
$\mathrm{Ab} / \mathrm{O}$ & $0.01-0.4$ & 27.49 & 1 & 11.22 & 28 \\
$\mathrm{Ab} / \mathrm{S}-\mathrm{BP}$ & $0.1-0.7$ & 26.29 & 10 & 14.54 & 36 \\
$\mathrm{Or}$ & 2 & 27.95 & 14 & 15.15 & 90 \\
$\mathrm{Hapl} / \mathrm{D}$ & $0.04-0.33$ & 26.71 & 9 & 13.33 & 58 \\
$\mathrm{RhyoK} / \mathrm{S}$ & $0.11-0.45$ & 27.55 & 10 & 11.37 & 109 \\
$\mathrm{RhyoP} / \mathrm{S}$ & $0.07-0.51$ & 27.55 & 4 & 11.24 & 37 \\
$\mathrm{Rhyo} / \mathrm{Oc}$ & $0.02-0.59$ & 26.28 & 15 & 12.55 & 137 \\
\hline
\end{tabular}

error in italic is based on the last digit.

literature data are summerized by Richet et al. (2000). In detail:

Ab/O: Orlova (1963), Ab/S-BP: Silver and Stolper (1989),

Or, RhyoK/S, Rhyo/P/S: Silver et al. (1990), Hapl/D:

Dingwell et al. (1996), and Rhyo/Oc: Ochs and Lange

(1999). 
FigureFig. 1

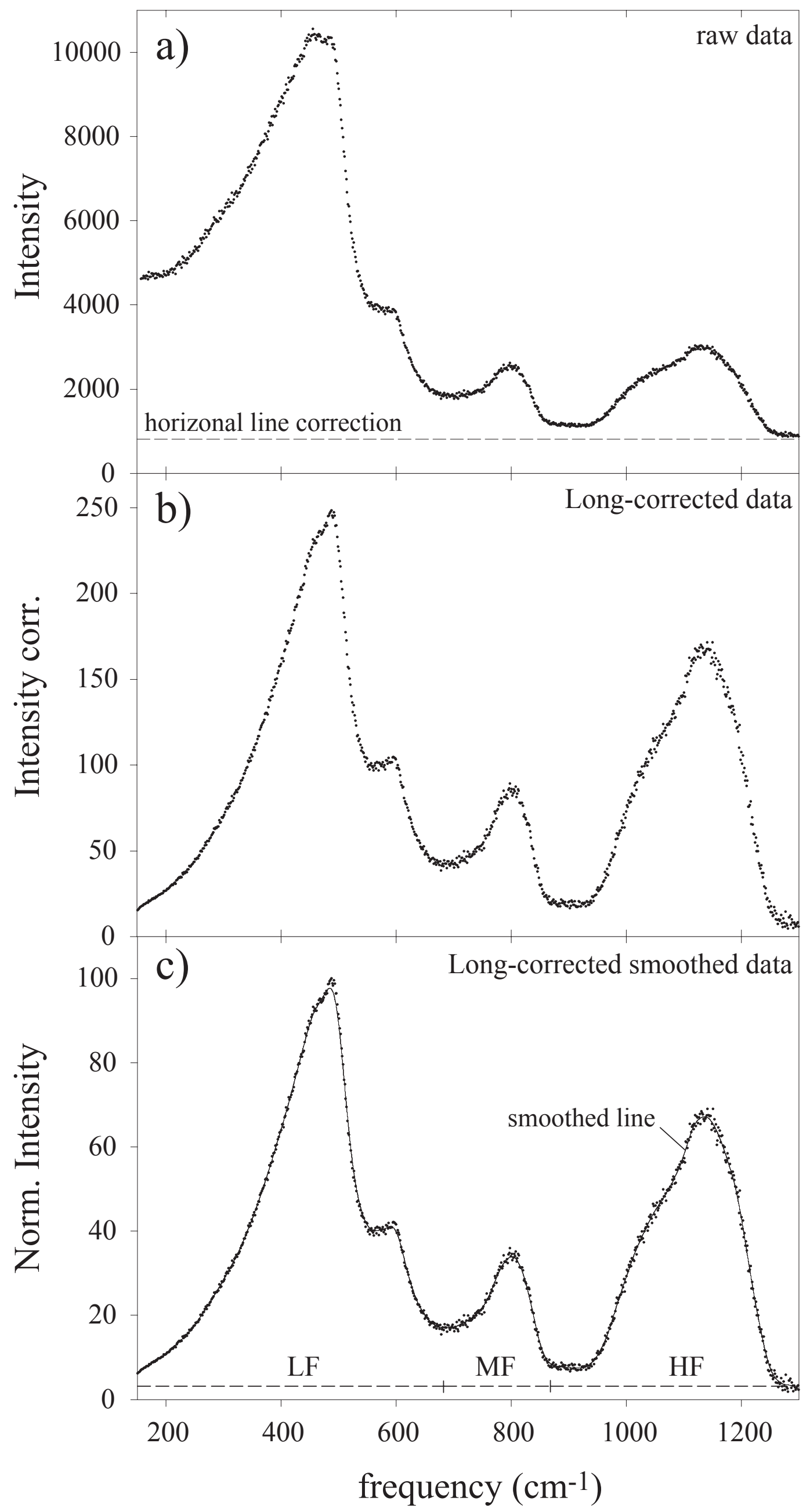




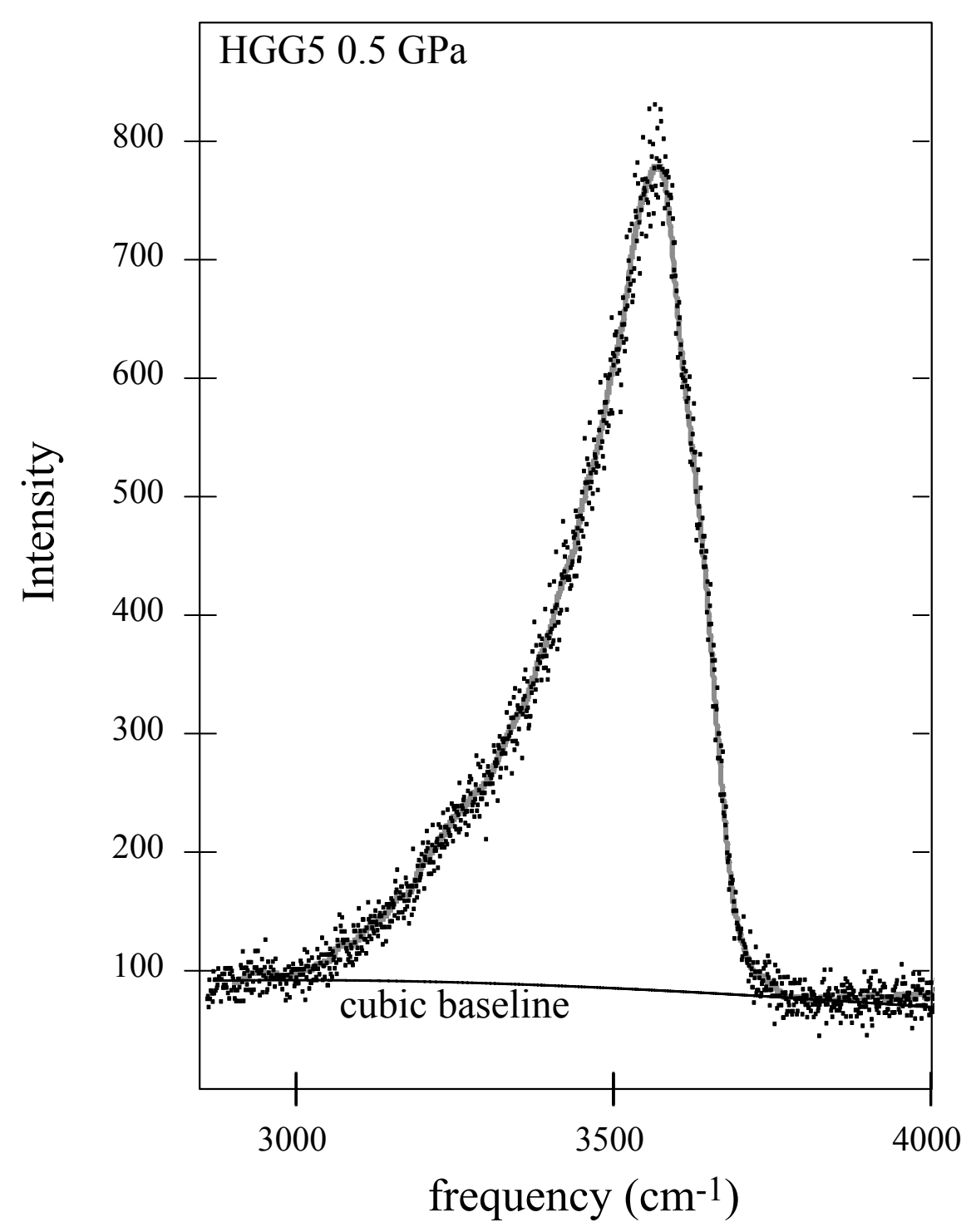

Figure层. 2 


\section{igure 3}

Click here to download high resolution image

Fig. 3

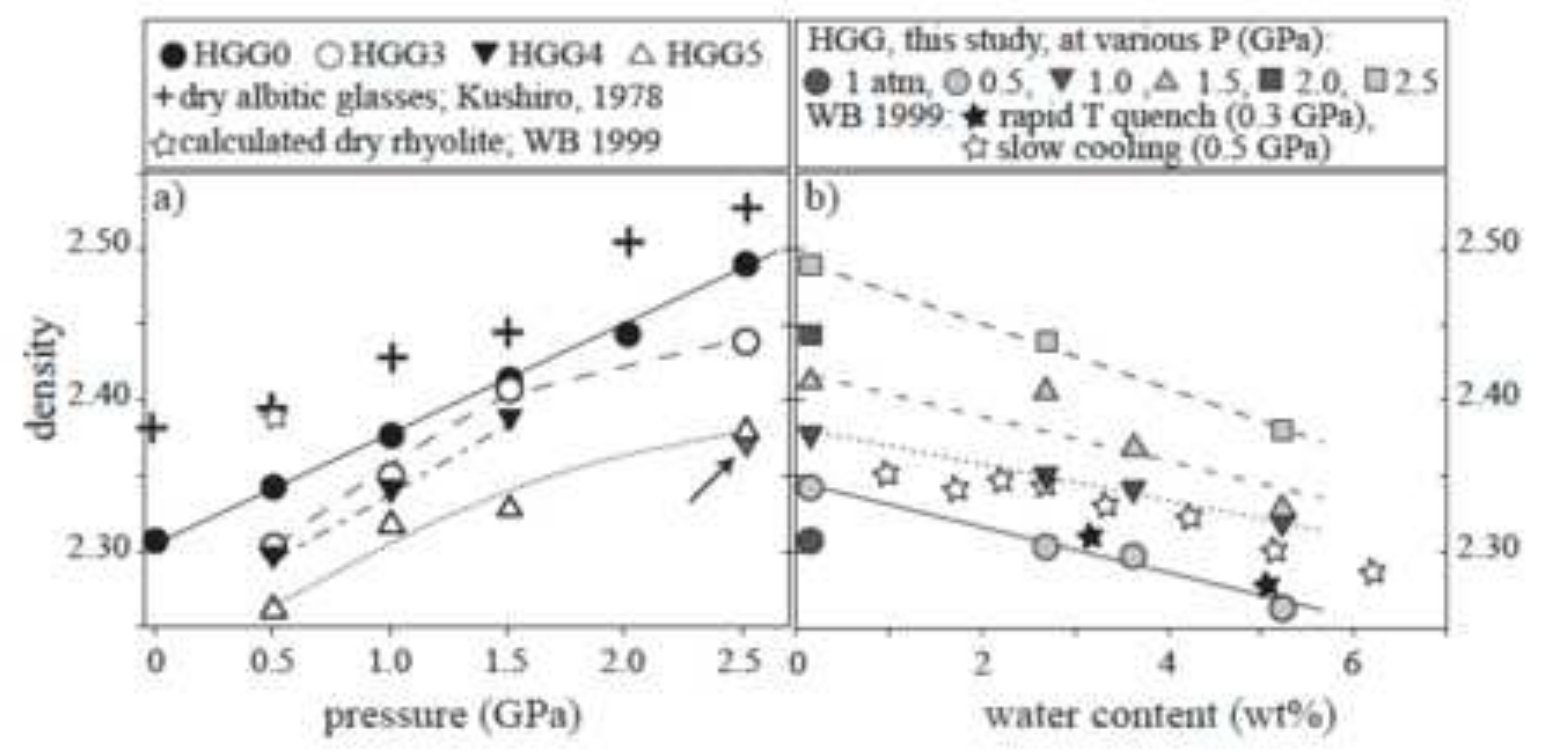




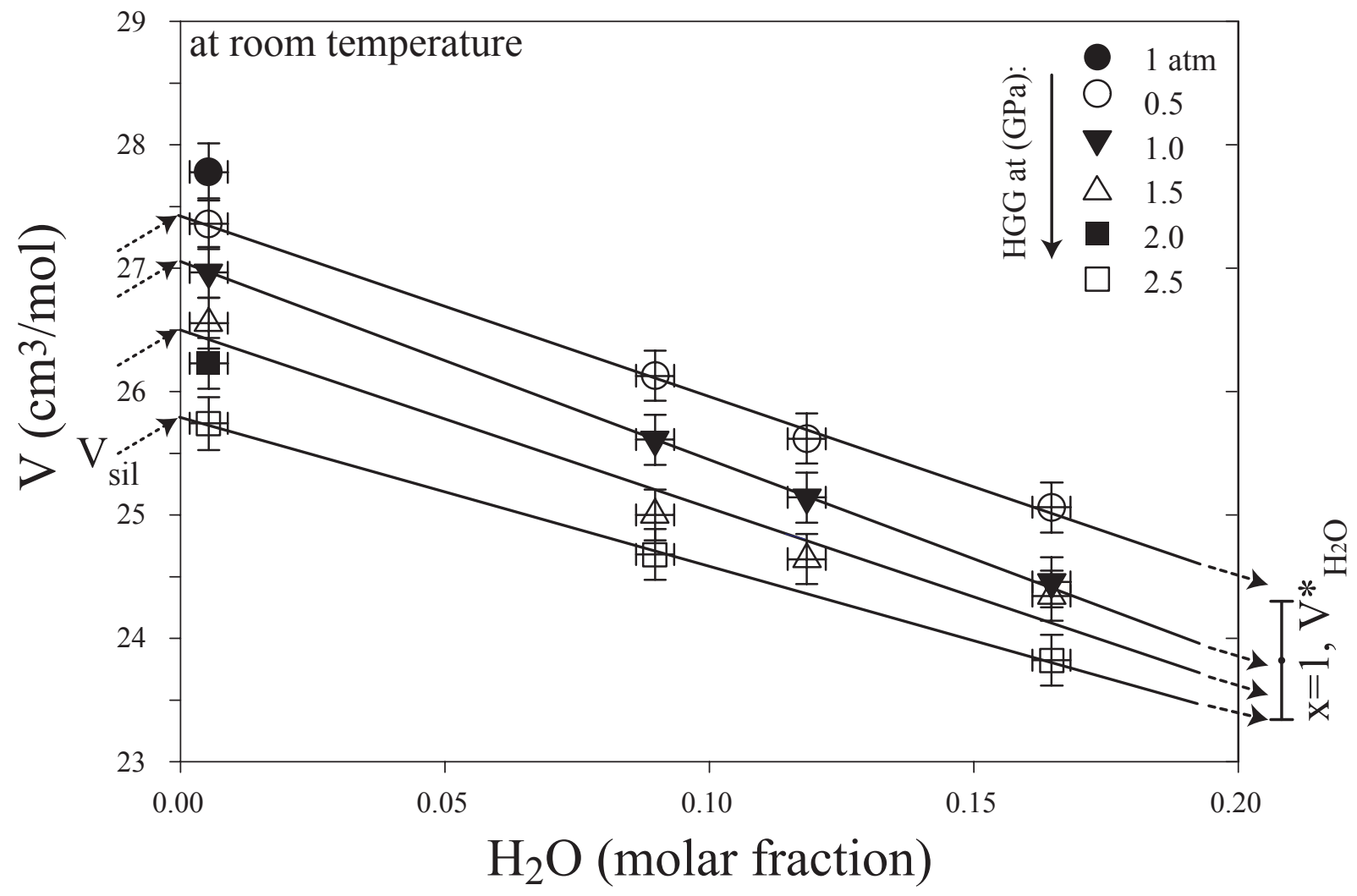




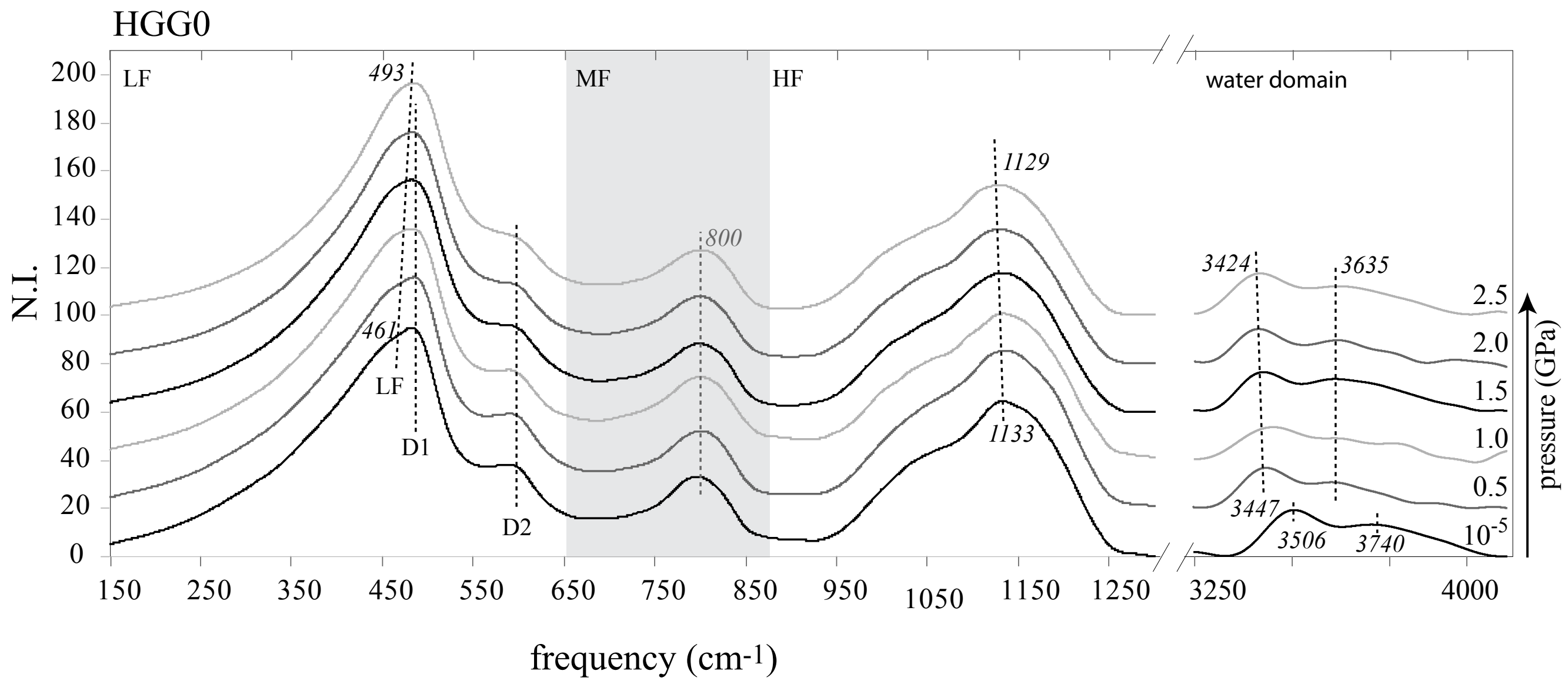




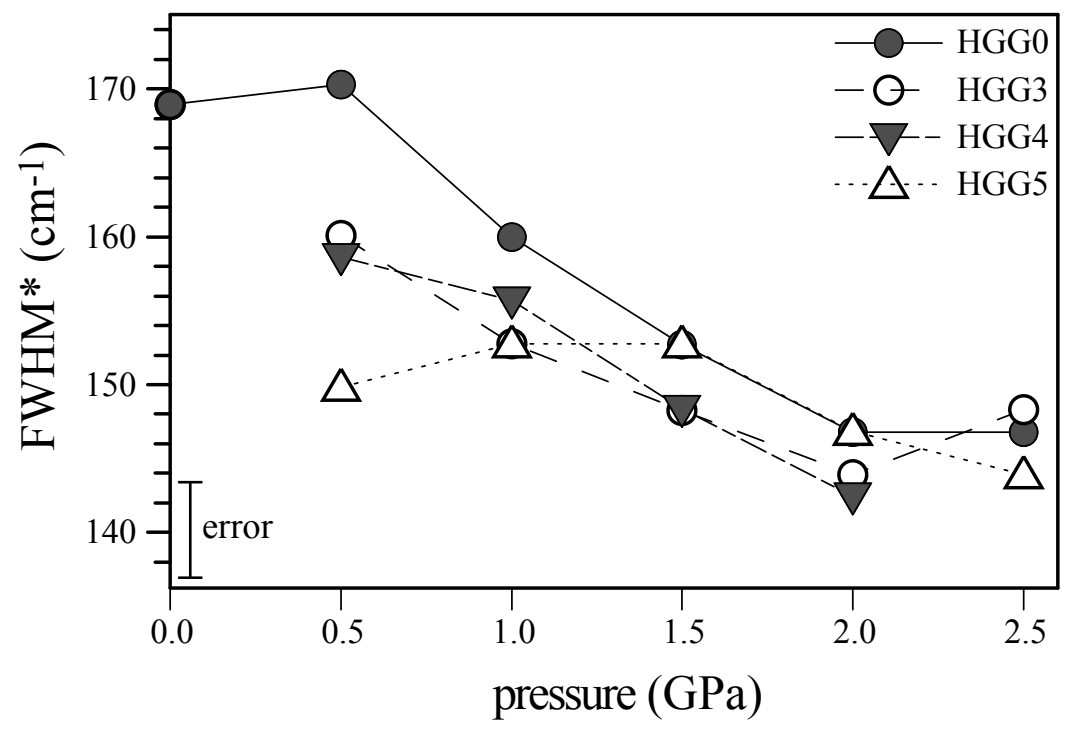




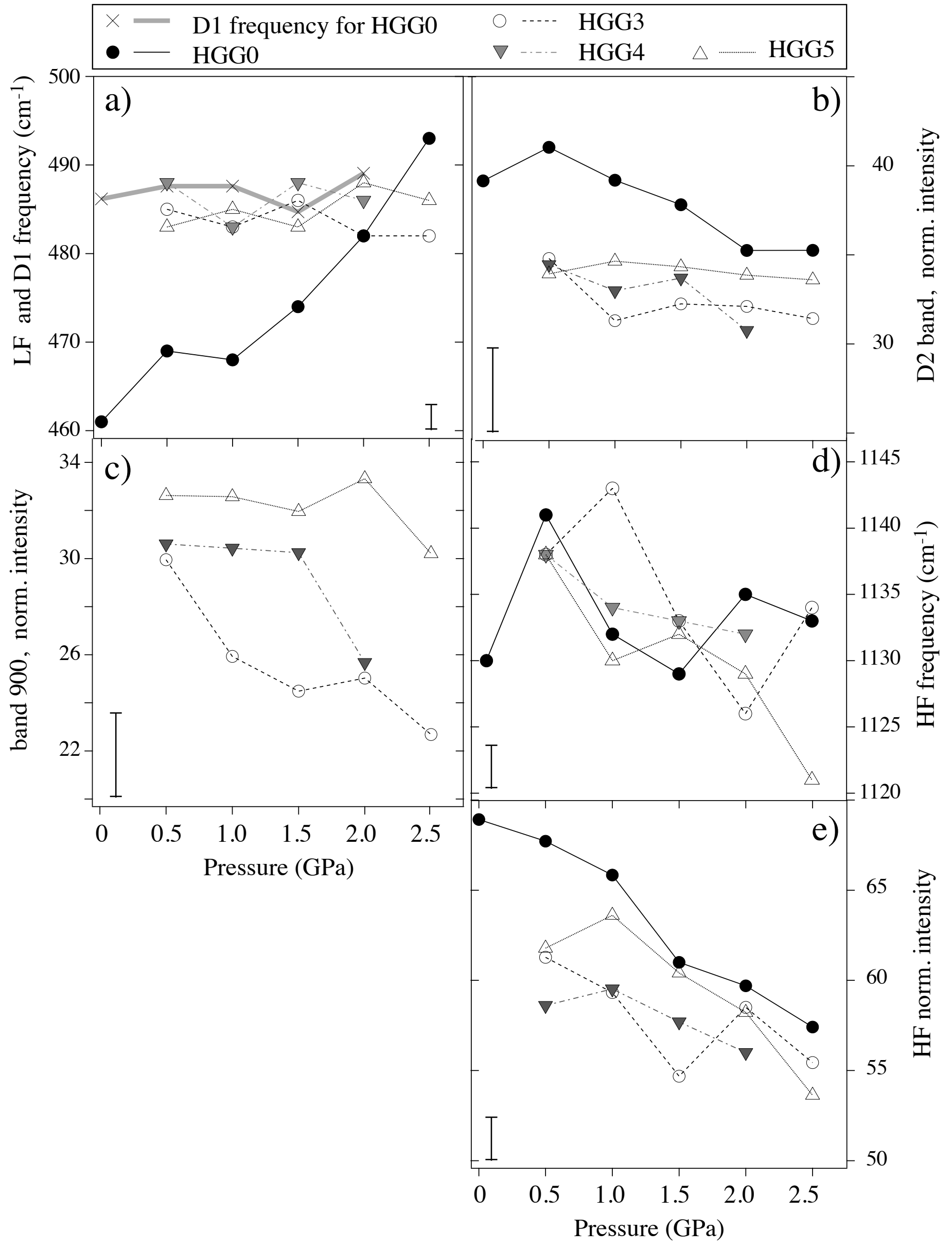


Figure 10

Click here to download high resolution image

Fig. 10

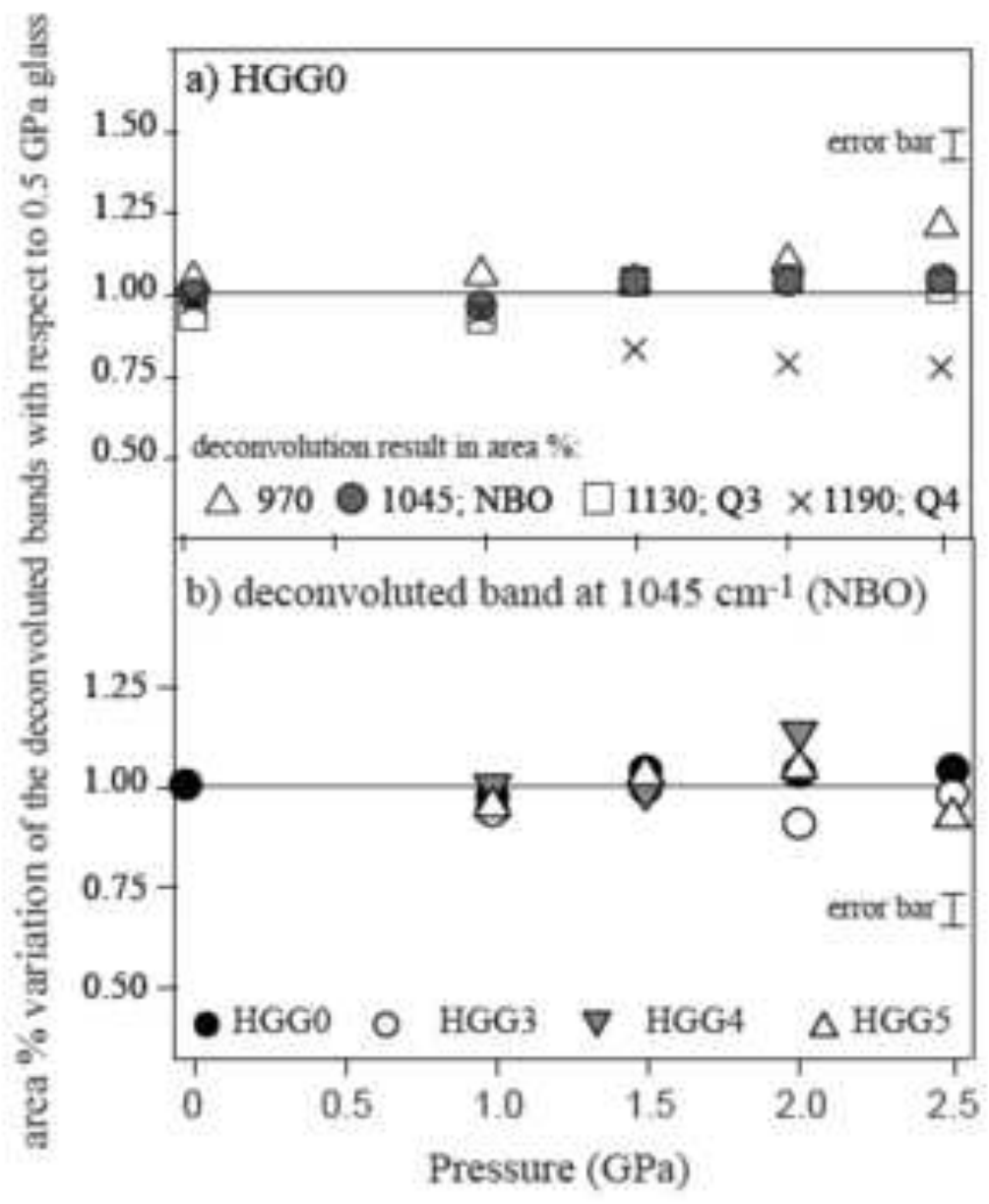




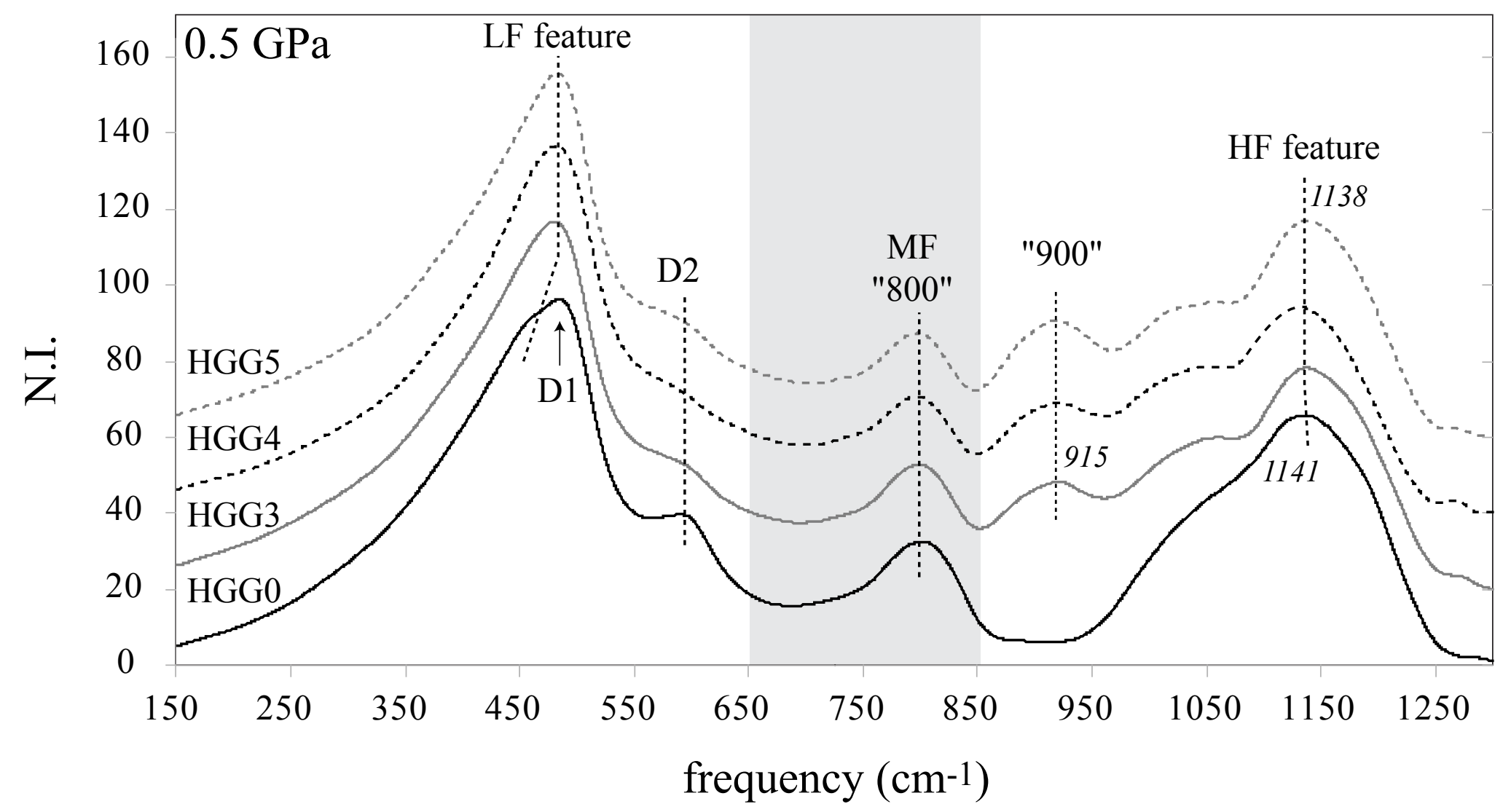




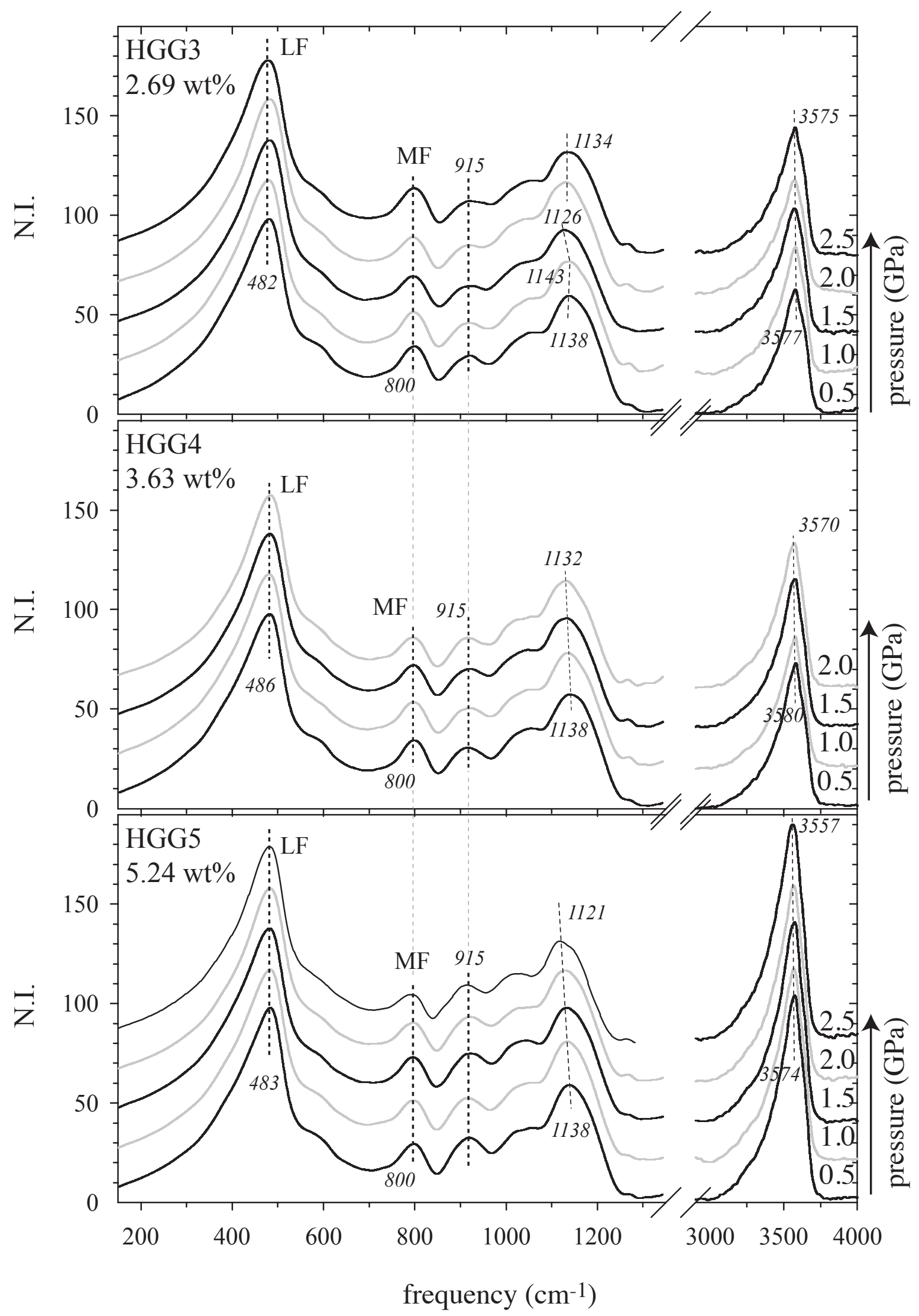


WATER POOR
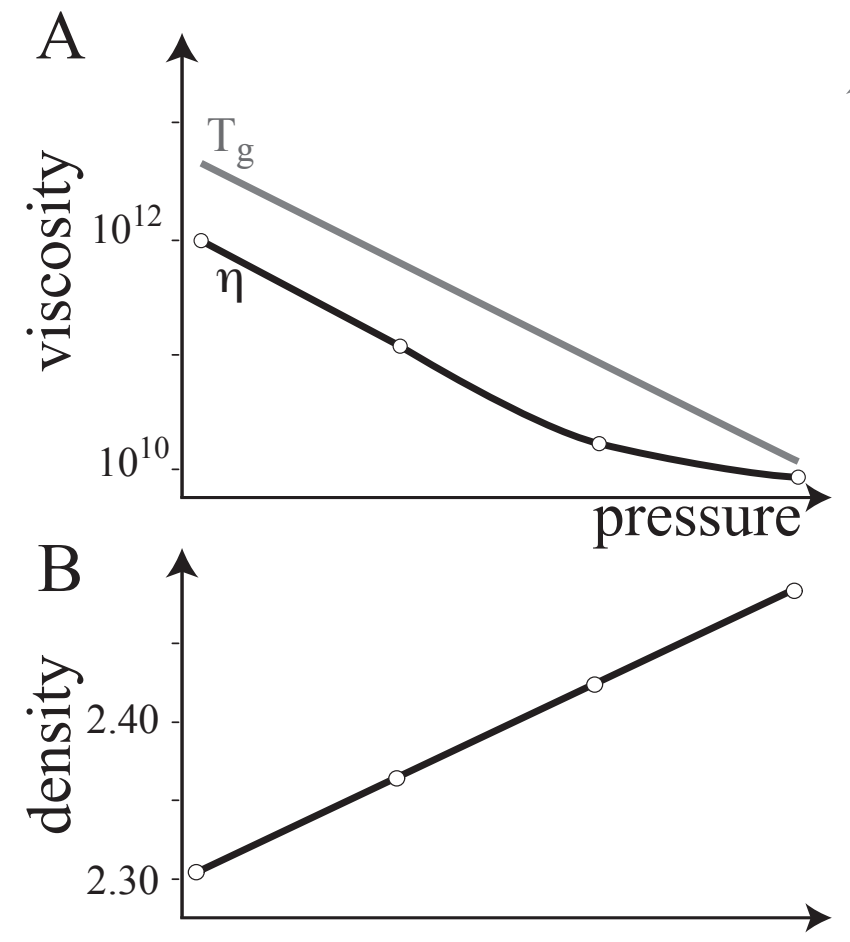

WATER RICH
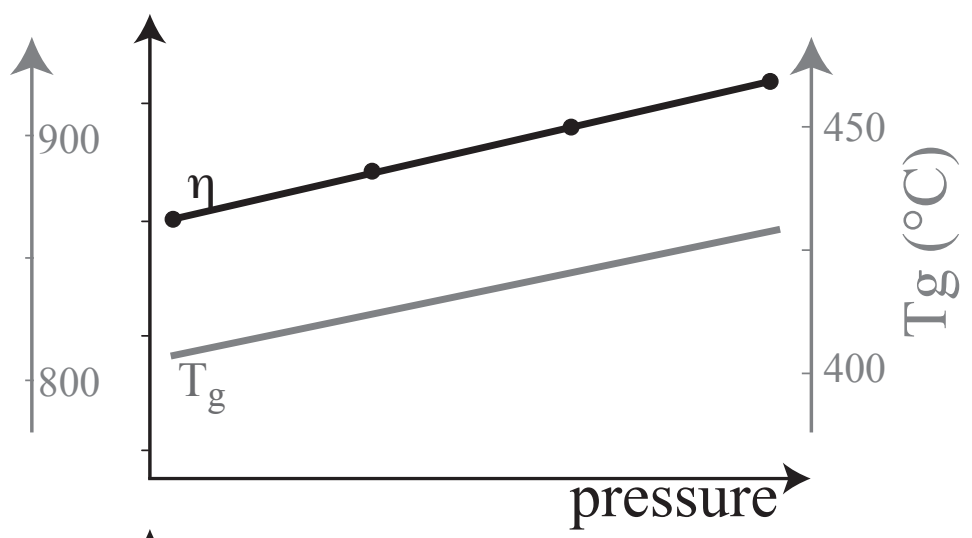

2.40

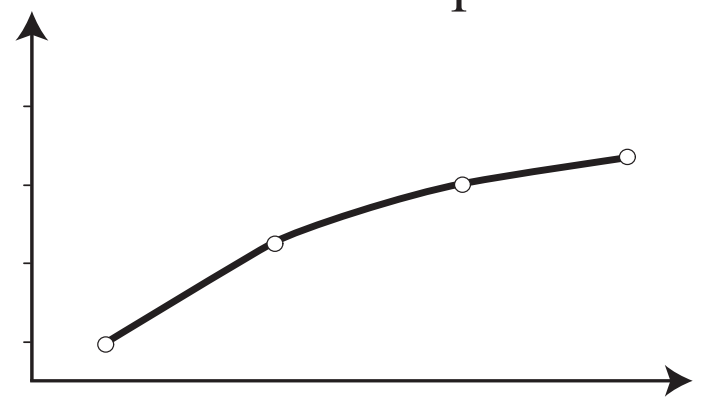

C

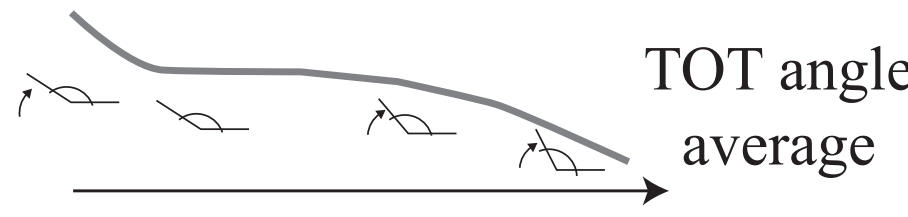

vAl

D $0 \%$

Malfait et al.

pressure (2012)
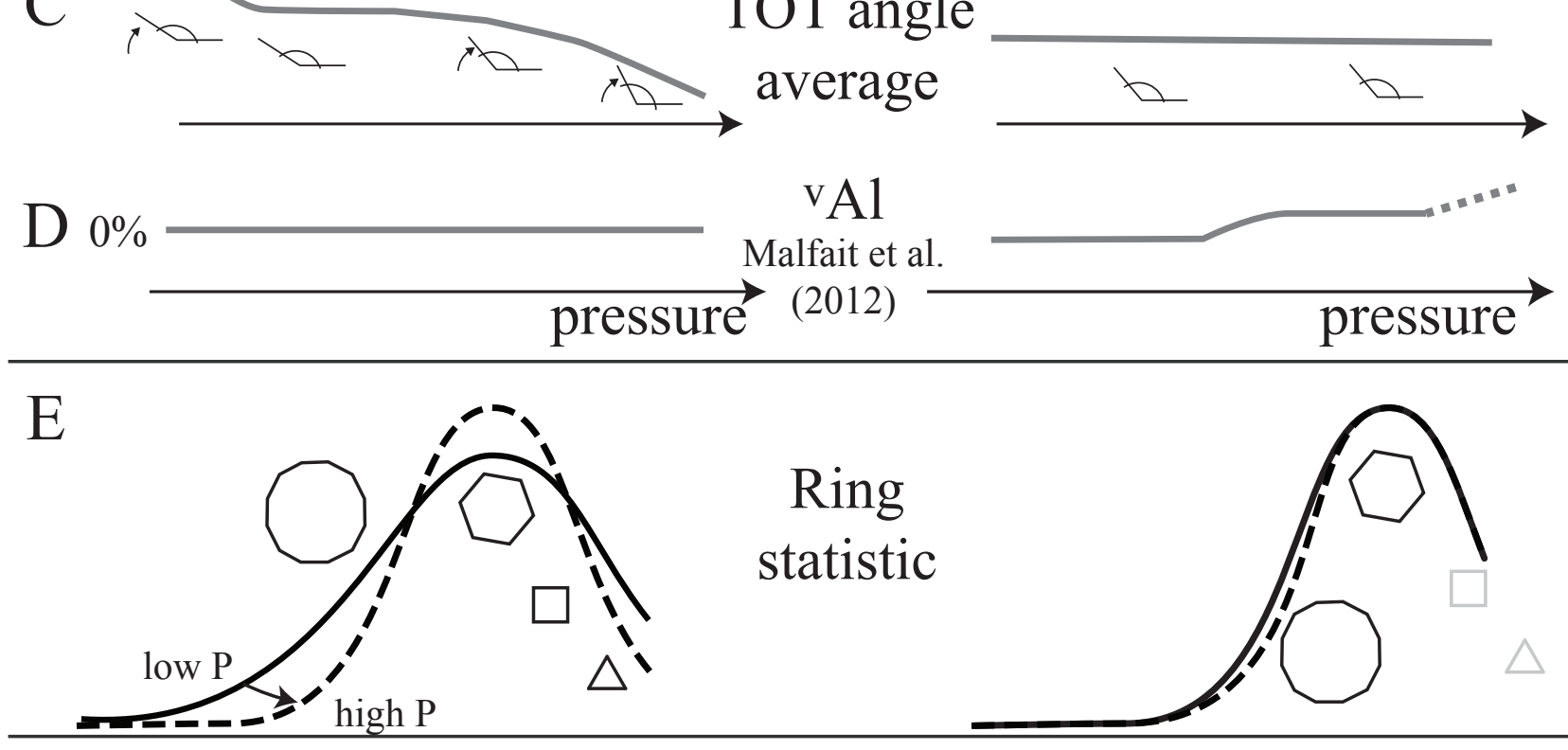

F

enhancement of

H-bonding

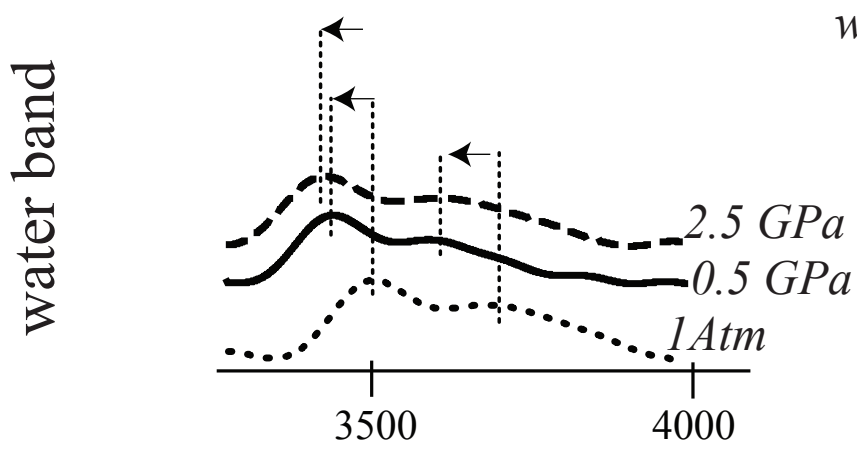

with $P$

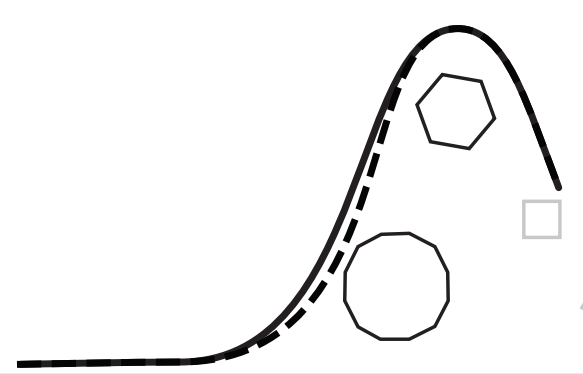

\section{of}

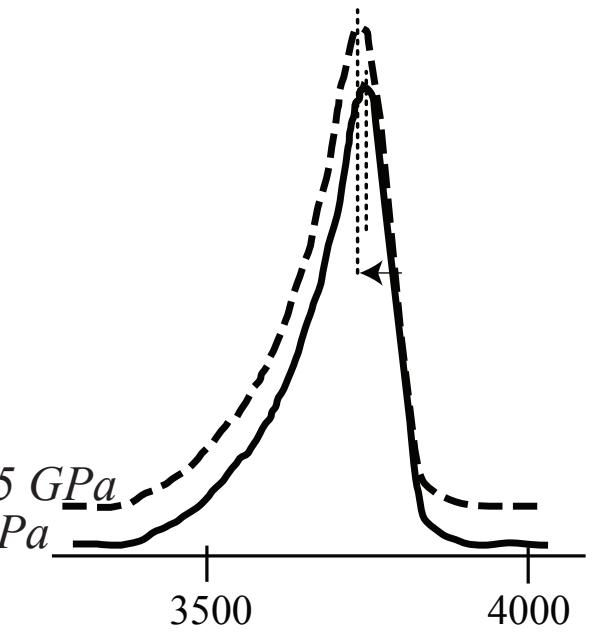

$2.5 \mathrm{GPa}$
$0.5 \mathrm{GPa}$ 